\title{
Influence of Overcrowding in the Emergency Department on Return Visit within $72 \mathrm{H}$
}

\author{
Dong-uk Kim ${ }^{1}$, Yoo Seok Park ${ }^{1}$, Joon Min Park ${ }^{2}$, Nathan J. Brown ${ }^{3,4}$, Kevin Chu ${ }^{3,4}$, \\ Ji Hwan Lee ${ }^{1}$, Ji Hoon Kim ${ }^{1}$ and Min Joung Kim ${ }^{1, *}$ \\ 1 Department of Emergency Medicine, Yonsei University College of Medicine, 50 Yonsei-ro, Seodaemun-gu, \\ Seoul 03722, Korea; KDU919@yuhs.ac (D.-u.K.); PYS0905@yuhs.ac (Y.S.P.); KEROKEROPI@yuhs.ac (J.H.L.); \\ JICHOON81@yuhs.ac (J.H.K.) \\ 2 Department of Emergency Medicine, Inje University Ilsan Paik Hospital, 170 Juhwa-ro, Ilsanseo-gu, \\ Goyang-si, Gyeonggi-do 10380, Korea; aero7@outlook.kr \\ 3 Emergency and Trauma Centre, Royal Brisbane and Women's Hospital, Butterfield Street, Herston QLD 4029, \\ Australia; nathan.brown3@health.qld.gov.au (N.J.B.); Kevin.Chu@health.qld.gov.au (K.C.) \\ 4 Faculty of Medicine, The University of Queensland, Brisbane QLD 4072, Australia \\ * Correspondence: boringzzz@yuhs.ac; Tel.: +82-2-2228-2460; Fax: +82-2-2227-7908
}

Received: 23 March 2020; Accepted: 7 May 2020; Published: 9 May 2020

\begin{abstract}
This study was conducted to determine whether overcrowding in the emergency department (ED) affects the occurrence of a return visit (RV) within $72 \mathrm{~h}$. The crowding indicator of index visit was the average number of total patients, patients under observation, and boarding patients during the first 1 and $4 \mathrm{~h}$ from ED arrival time and the last $1 \mathrm{~h}$ before ED departure. Logistic regression analysis was conducted to determine whether each indicator affects the occurrence of RV and post-RV admission. Of the 87,360 discharged patients, 3743 (4.3\%) returned to the ED within $72 \mathrm{~h}$. Of the crowding indicators pertaining to total patients, the last $1 \mathrm{~h}$ significantly affected decrease in RV $(p=0.0046)$. Boarding patients were found to increase RV occurrence during the first $1 \mathrm{~h}(p=0.0146)$ and $4 \mathrm{~h}(p=0.0326)$. Crowding indicators that increased the likelihood of admission post-RV were total number of patients during the first $1 \mathrm{~h}(p=0.0166)$ and $4 \mathrm{~h}(p=0.0335)$ and evaluating patients during the first $1 \mathrm{~h}(p=0.0059)$. Overcrowding in the ED increased the incidence of RV and likelihood of post-RV admission. However, overcrowding at the time of ED departure was related to reduced RV.
\end{abstract}

Keywords: emergency department; crowding; return visit; admission; patient satisfaction; quality of healthcare

\section{Introduction}

Return visit (RV) is often used as a quality indicator for the emergency department (ED), because the general idea is that $R V$ is caused by premature discharges at the initial visit, missed diagnosis, or failure of treatment or discharge planning [1-5]. RV not only delays proper treatment of patients but also increases resource use and medical costs [6,7]. The causes of RV are very complex and multifactorial. Besides medical error, misdiagnosis, and delayed diagnosis as doctor-related factors, other factors such as disease progression, lack of improvement, or patient's concern and fear about their condition contribute to RV [4,5,8-10]. Some studies have addressed the relationship between RV and the healthcare system, such as hospital bed shortages and ED overcrowding [11-13].

Worldwide, ED overcrowding is a healthcare problem, and has led to increased misdiagnosis and medication errors [14-18]. Emergency physicians must always provide timely first aid to emergent patients; therefore, when the ED is overcrowded, doctors hasten the discharge process of patients to prepare an empty bed for new emergent patients. Such an increase in premature discharge may sometimes lead to inadequate discharge, which can increase the rate of RV. To date, few studies 
have explored the relationship between ED overcrowding and RV, and no significant effect has been reported $[8,19,20]$. Verlest et al. reported that the number of patients occupying ED during the first $8 \mathrm{~h}$ of the index visit was unassociated with the occurrence of RV [19]. Hu et al. compared the occurrence of the RV with and without admission, and found that the number of whole-shift patients of the index visit did not differ between the two groups [8]. In a study by Hayward et al., ED occupancy level was not a significant factor for predicting admission in RV patients [20]. These results can differ on the basis of the definition of ED overcrowding. Therefore, a more sophisticated definition of the overcrowded state of index visits is needed to clarify the correlation between ED overcrowding and $\mathrm{RV}$. ED overcrowding at the time of arrival of an index visit may affect RV, but overcrowding at the time of departure may be a more important factor. Moreover, in the ED, patients who are undergoing emergency evaluations and those awaiting a hospital bed after being advised hospitalization are together, and the impact of the number of patients under evaluation and the number of potential inpatients on the occurrence of RV may differ.

In this study, we specifically defined criteria for ED overcrowding, considering several time points of index visits and the composition of patients occupying the ED. The primary objective was to identify the effect of ED overcrowding at index visit on the occurrence of RV. The secondary objective was to determine whether ED overcrowding of index visit is a factor that causes RV with admission (RVA) compared with RV with no admission (RVNA). We hypothesized that overcrowded ED at the index visit would increase the occurrence of RV and would be a factor that induces RVA rather than RVNA.

\section{Materials and Methods}

\subsection{Study Design and Setting}

We conducted a retrospective observational study at the ED in a 2000-bed tertiary-care center, located within the capital of South Korea. The ED is divided into two areas as adult and pediatric ED; the adult ED covers patients older than 16 years. On average, 70,000 patients visit the adult ED annually and admission rate is approximately $24 \%$. We included patients who were treated and discharged home in the adult ED between October 2017 and June 2019. We excluded patients who were transferred to other hospitals or discharged as hopeless patients after ED treatment. Furthermore, to analyze the first index visit, we designated visits within the period to define "short-term revisit" from the prior visit and these were excluded. All data were anonymized and were collected from the hospital information system, and this study was exempted from the obligation to obtain informed consent by the institutional review board committee of this hospital.

In our hospital, on patient arrival at the ED, the triage nurse classifies the acuity of patient using the Korean Triage and Acuity Scale (KTAS), a five-level classification system ( 1 = resuscitation, $2=$ emergency, $3=$ urgent, $4=$ less-urgent, $5=$ non-urgent). If the patient is unstable, such as with altered mental status or shock, the patient is directly sent to the monitoring area and treatment is initiated. Otherwise, the patient is examined by an emergency doctor in the doctor's office and assigned to the monitoring area, bed area, chair area, or fast-track according to the patient's condition and medical problems. The monitoring area has 15 beds, including two beds for resuscitation, and the bed area has 26 beds. There were 20 recliner chairs in the chair area, and the fast-track area has no specified seats. In each area, emergency doctors initially evaluate and treat patients, and they consult a specialist if the patient needs to be hospitalized or needs special care, including emergency procedures. Patients who are identified for hospitalization are taken to the hospital wards; however, in the absence of empty hospital beds, patients are admitted in the ED until a hospital bed becomes available. This ED does not operate any system to follow up the patients discharged from the ED; therefore, patients who need additional care after discharge are scheduled for outpatient clinic visits at the time of ED discharge. 


\subsection{Definition and Data Processing}

We defined the RV as returning to the ED within a short-term period of $72 \mathrm{~h}$ from the ED departure time of the index visit. Despite a lack of supporting evidence, $72 \mathrm{~h}$ is the time period used in $63 \%$ of previously reported studies [21]. Furthermore, the RV was divided into the RVA and RVNA, according to the treatment outcome when the patient returned to the ED. Patients who died in the ED or were transferred to another hospital were included in the RVA.

To define the overcrowding of the ED, we decided to consider the number of total patients occupying the ED, the number of evaluating patients to estimate the overload in the throughput of the ED, and the number of boarding patients to reflect the blocking of ED output. For this, we adapted three time components: ED arrival time, disposition (admission or discharge) decision time, and the ED departure time of all patients who visited the adult ED during the study period. From these time components of each patient, we summed up all relevant numbers and evaluating (from ED arrival to the disposition decision) and boarding (in the ED, awaiting a hospital bed after the decision to admit) patients by reconstructions set at 10 min intervals (Figure 1).

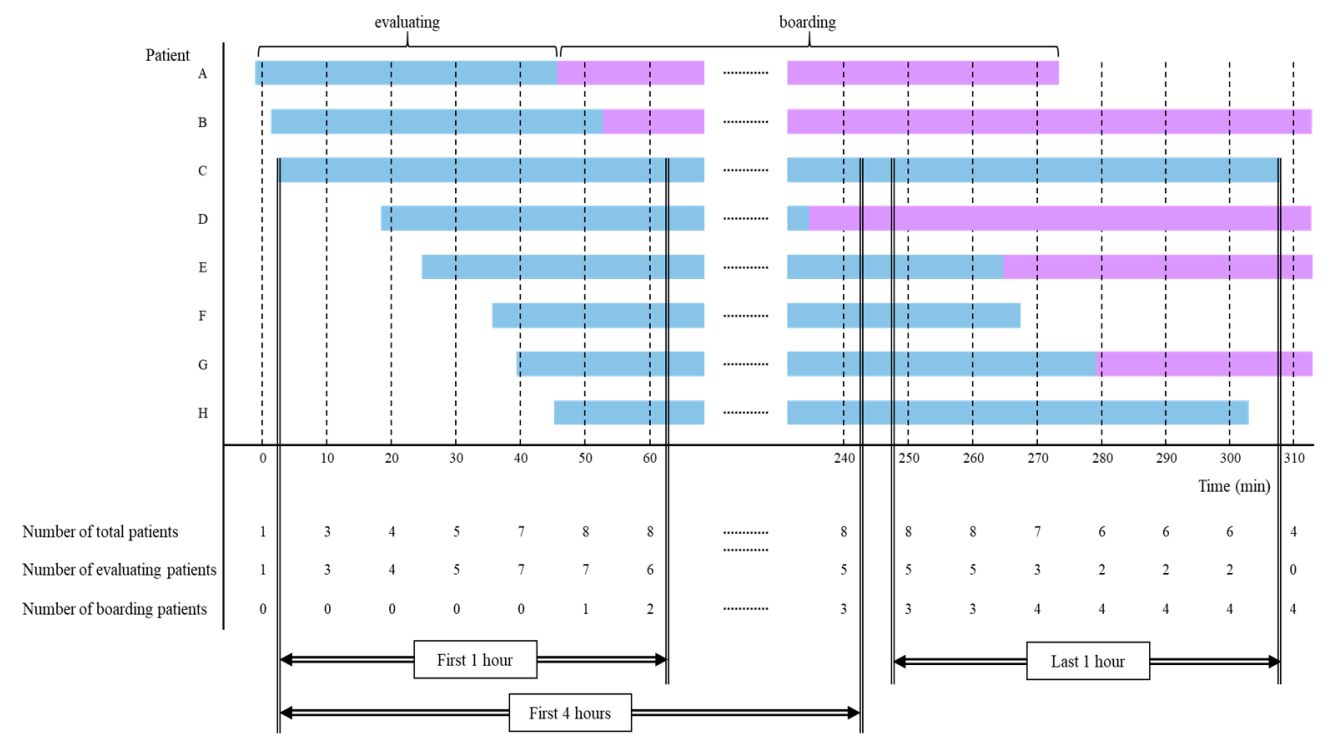

Figure 1. Data processing to reconstruct crowding indicators from an individual patient's time-related factors. Bars represent the stay of individual patients in the emergency department; the blue bar represents an evaluating phase and the purple bar indicates the boarding phase. If the patient's stay spanned the time of the $10 \mathrm{~min}$ interval, the patient was added to the number of patients at that time. For crowding indicators, the average number of patients during the first $1 \mathrm{~h}$ and $4 \mathrm{~h}$ and the last $1 \mathrm{~h}$ were calculated. For example, in Patient $C$, the average number of total patients during the first $1 \mathrm{~h}$ was $(3+4+5+7+8+8) / 6=5.8$ and the average number of boarding patients during the last $1 \mathrm{~h}$ was $(3+3+4+4+4+4) / 6=3.7$.

In this ED, the average time from the ED arrival to the decision of admission or discharge was $4 \mathrm{~h}$. Therefore, we determined the level of ED crowding at the time of the index visit as the average number of occupying patients for $4 \mathrm{~h}$ from the time of ED arrival. Moreover, the first $1 \mathrm{~h}$ from ED arrival and the last $1 \mathrm{~h}$ before ED departure were designated as additional timeframes for calculating the crowding indicators. With regard to total patients, the average number of total patients during the first $4 \mathrm{~h}$ (TF4h), the first $1 \mathrm{~h}$ (TF1h), and the last $1 \mathrm{~h}$ (TL1h) were calculated. Similarly, three indicators were calculated for each evaluating and boarding patient; the average number of evaluating patients during the first $4 \mathrm{~h}$ (EF4h), the first $1 \mathrm{~h}$ (EF1h), and the last $1 \mathrm{~h}$ (EL1h); and the average number of boarding patients during the first $4 \mathrm{~h}(\mathrm{BF} 4 \mathrm{~h})$, the first $1 \mathrm{~h}(\mathrm{BF} 1 \mathrm{~h})$, and the last $1 \mathrm{~h}(\mathrm{BL} 1 \mathrm{~h})$. If the patient remained in the ED for less than the time span of crowding indicators ( 1 and $4 \mathrm{~h}$ ), the average value during the patient's stay was used for crowding indicators. 
We assumed that the influence of overcrowding would not increase proportionally with the number of patients in the ED, and that the number of patients would not have a negative effect, to a certain extent. The number of patients would begin to affect overcrowding from a certain point; however, there are no previous studies that investigated this critical point. In some studies, ED occupancy rate was divided into four quartiles, and the quartile with the highest occupancy was defined as overcrowding that exceeded the treatment capacity of the ED [19,22]. We also designated the third quartiles of each of the total, evaluating, and boarding number of patients as the critical points, and defined the ED as overcrowded when the level of crowding indicators of the index visit exceeded these critical points.

\subsection{Study Variables}

All variables were retrieved from hospital information system and electronic medical records. We collected patient demographic data (sex and age), factors of ED visit (mode of transport (self or ambulance), direct ED visit, or transfer from another hospital), and factors of patient clinical severity such as urgency level rated by KTAS and the presence of severe medical conditions designated on the basis of the survival risk ratio by the central medical center under the Ministry of Health and Welfare. The following characteristics of the patient's problem and ED treatment were also collected: the chief complaint; the reason of the ED visit (medical problem or not); whether the attending physician was involved for the patient care; assigned treatment area; whether specialty consultation was requested; ED arrival time and date; time from ED arrival to designated area (door to area time); length of stay (LOS) in the ED; and whether specific evaluation such as blood tests, computed tomography (CT), and magnetic resonance imaging (MRI) were conducted in the ED. For analysis, we categorized arrival time into four time zones (0-6, 6-12, 12-18, and 18-24) and ED visit date into binominal variables of weekdays and weekends, as well as into nominal variables about season (December to February as winter, March to May as spring, June to August as summer, and September to November as autumn). Crowding indicators of index visit were transformed into binominal variables (overcrowded or not) on the basis of the critical point (the third quartile value).

\subsection{Statistical Analysis}

We first compared the patient characteristics of index visits with and without RVs. The nominal variables were compared by chi-squared test and expressed in number and percentage. The continuous variables were analyzed by Mann-Whitney $U$ test considering the skewness, and were presented as median and interquartile range (IQR). The univariable logistic regression was used to identify the factors affecting RV incidence, and the multivariable logistic regression was undertaken by adjusting confounding variables with $p$-value $<0.1$ as a result of univariable regression. Adjusted odds ratio (OR) with 95\% confidence interval (CI) of each crowding indicator was presented. Second, the characteristics of RVA and RVNA were compared in order to investigate whether overcrowding at the index visit showed significant differences between RVA and RVNA. Moreover, we identified the effect of overcrowding on RVA through multivariable logistic regression by adjusting confounding variables. The analysis was conducted using SAS (version 9.4, SAS Inc, Cary, NC, USA), and determined to be statistically significant when the $p$-value was $<0.05$.

\section{Results}

There were a total 123,619 ED visits during the study period (Figure 2). The ED treatment resulted in 29,611 (24.0\%) admissions, 879 deaths, 1763 transfers to other hospitals, and 19 hopeless discharges, which were excluded from the analysis. Of the 90,347 discharges, 2987 cases with a history of prior ED care within $72 \mathrm{~h}$ were excluded. Finally, 87,360 index visits were included in the analysis; $4.3 \%$ (3743) of these index visits led to RV within $72 \mathrm{~h}$, and 1113 (29.7\% of RV) were admitted as a result of RV. 


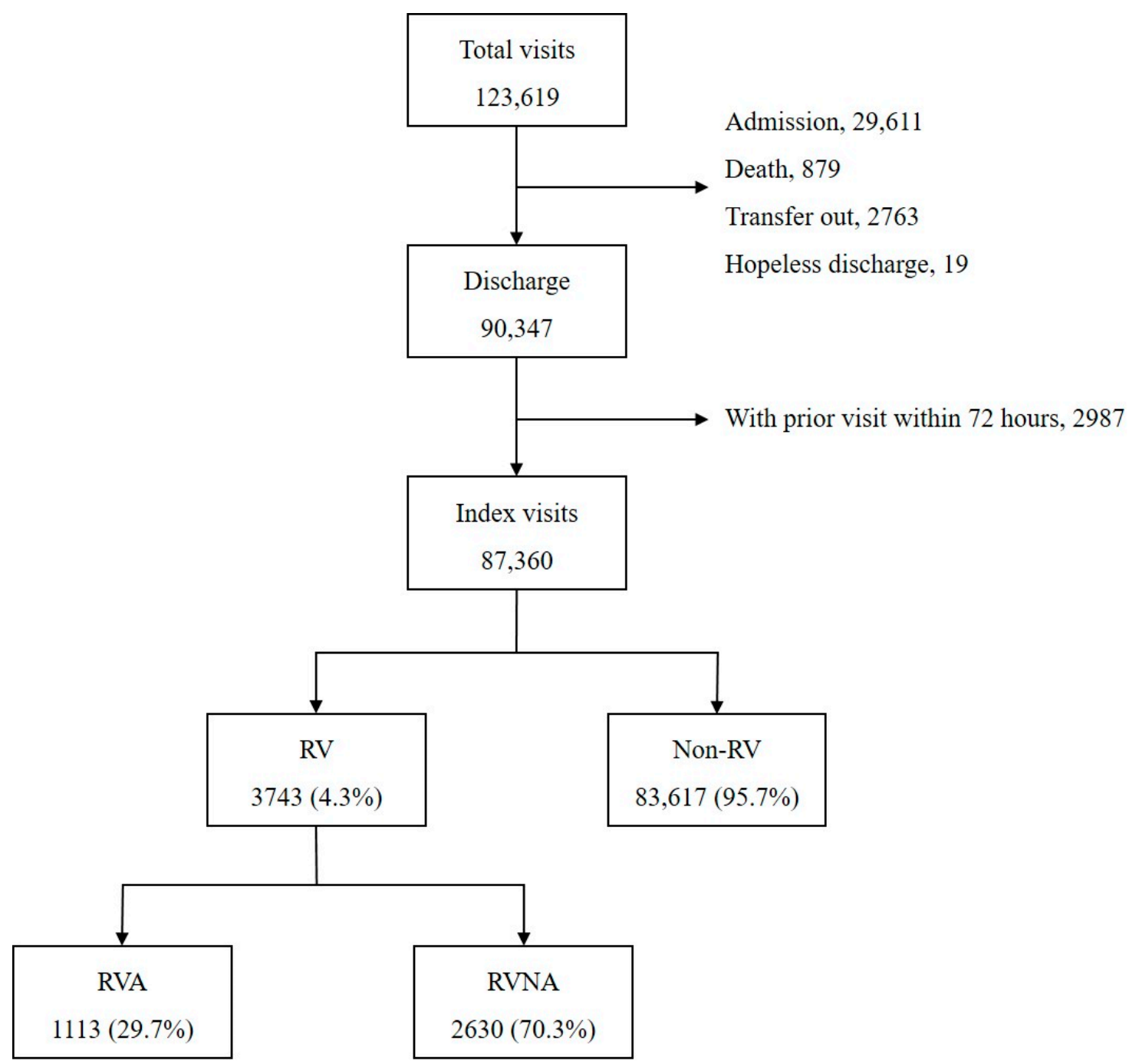

Figure 2. Study patient disposition. RV, return visit; RVA, return visit with admission; RVNA, return visit with no admission.

The count of measurements at 10 min intervals for total, evaluating, and boarding patients was 91,872 . The hourly distribution by day of week of the number of occupying patients is shown in Figure 3. The number of the total and evaluating patients were lowest at dawn and highest in the afternoon, with similar patterns for each day of the week. The number of boarding patients gradually increased from Monday to Friday, and then decreased on Friday afternoon. The median (IQR) value was 56 (44-68) for the total number of patients, 35 (26-44) for the number of evaluating patients, and 14 (8-26) for the number of boarding patients. Therefore, the third quartile, the critical point of overcrowding, was 68,44 , and 26 , for total, evaluating, and boarding indicators, respectively.

\subsection{Comparison between $R V$ and Non-RV}

Patient characteristics of index visits according to the RV occurrence are compared in Table 1. There were more men $(46.2 \%$ vs. $43.2 \%, p=0.0004)$ and older patients $(p<0.0001)$ in the RV group. The proportion of patients with KTAS 3 and 4 was higher in the RV group, whereas the proportion of KTAS 5 was higher in the non-RV group $(p<0.0001)$. The proportion of non-medical problems in the RV group was $9.7 \%$, which was significantly lower than the $22.4 \%$ in the non-RV group $(p<0.0001)$. More laboratory study, X-rays, CT scans, and specialty consultations were performed in the RV group, and the median ED LOS was 224.5 (139.2-368.1) $\mathrm{min}$ in the RV group, which was longer than the 184.6 $(116.5-305.2) \mathrm{min}$ in the non-RV group $(p<0.0001)$. For crowding indicators of total patients, TF1h 
( $24.7 \%$ vs. $26.4, p=0.0198)$ and TL1h $(24.0 \%$ vs. $26.2 \%, p=0.0030)$ were fewer in the RV group, and TF4h did not show significant difference. All three indicators of evaluating patients were higher in the non-RV group: EF4h (30.5\% vs. $32.6, p=0.0060)$, EF1h $(30.0 \%$ vs. $32.3 \%, p=0.0147)$, and EL1h $(29.4 \%$ vs. $31.5, p=0.0076)$. For boarding indicators, more BF1h were in the RV group than non-RV group (20.8\% vs. 19.4, $p=0.0354)$. There was no significant difference in BF4h and BL1h between the two groups.

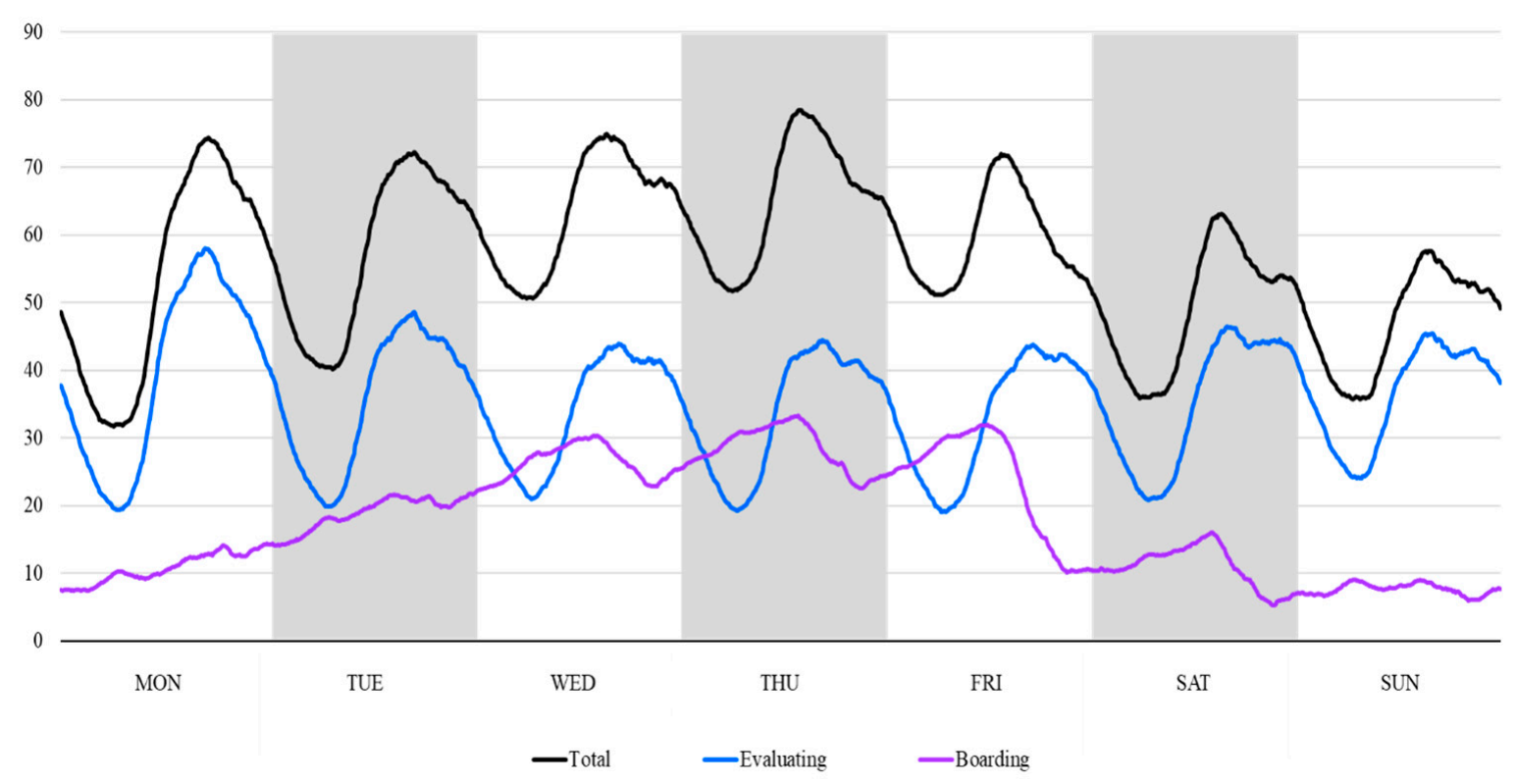

Figure 3. The hourly distribution by day of week of patients occupying the emergency department.

\subsection{Influence of ED Overcrowding on the RV Occurrence}

Multivariable logistic regression was conducted for each crowding indicator (Figure 4). Both TF4h and TF1h did not show a significant relation to RV occurrence, although TL1h was found to have a significant effect in decreasing RV occurrence (adjusted OR (95\% CI), $0.888(0.817-0.964), p=0.0046)$. In the indicators of evaluating patients, the effect of overcrowding on RV was not statistically significant. Both BF4h and BF1h were found to increase RV occurrence: adjusted OR (95\% CI), 1.099 (1.008-1.199), $p=0.0326$ for BF4h; $1.113(1.021-1.214), p=0.0146$ for BF1h. However, BL1h had no significant effect on RV occurrence. Other factors influencing the RV occurrence were age, gender, EMS, non-medical problem, complaint category, time of ED arrival, MRI evaluation, specialty consultation, and discharge against medical advice (DAMA). The result of univariable logistic regression for RV occurrence is presented in Appendix A, and the results of multivariable logistic regression of each crowding indicator are shown in Appendices B-D. 
Table 1. Comparison of patient characteristics of index visits according to the occurrence of return visit within $72 \mathrm{~h}$.

\begin{tabular}{|c|c|c|c|c|}
\hline \multicolumn{2}{|l|}{ Variables } & \multirow{2}{*}{$\begin{array}{c}\text { RV } \\
n=3743 \\
1087(29.0)\end{array}$} & \multirow{2}{*}{$\begin{array}{c}\begin{array}{c}\text { Non-RV } \\
n=83,617\end{array} \\
32,991(39.5)\end{array}$} & \multirow{2}{*}{$\begin{array}{c}p \text {-Value } \\
<0.0001\end{array}$} \\
\hline Age, $n(\%)$ & -39 & & & \\
\hline & $40-64$ & $1415(37.8)$ & $29,508(35.3)$ & \\
\hline & $65-79$ & $895(23.9)$ & $15,999(19.1)$ & \\
\hline & $80-$ & $346(9.2)$ & $5119(6.1)$ & \\
\hline Female, $n(\%)$ & & $2015(53.8)$ & $47,476(56.8)$ & 0.0004 \\
\hline Transfer in, $n(\%)$ & & $320(8.5)$ & $6818(8.2)$ & 0.3875 \\
\hline EMS, $n(\%)$ & & $858(22.9)$ & $15,781(18.9)$ & $<0.0001$ \\
\hline \multirow[t]{5}{*}{ KTAS, $n(\%)$} & 1 & $6(0.2)$ & $229(0.3)$ & $<0.0001$ \\
\hline & 2 & $207(5.5)$ & $4566(5.5)$ & \\
\hline & 3 & $797(21.3)$ & $15,801(18.9)$ & \\
\hline & 4 & $2277(60.8)$ & $48,931(58.5)$ & \\
\hline & 5 & $456(12.2)$ & $14,090(16.9)$ & \\
\hline Non-medical, $n(\%)$ & & $363(9.7)$ & $18,723(22.4)$ & $<0.0001$ \\
\hline \multirow[t]{9}{*}{ Complaint category, $n(\%)$} & Gastrointestinal & $813(21.7)$ & $14,498(17.3)$ & $<0.0001$ \\
\hline & General & $702(18.8)$ & $12,440(14.9)$ & \\
\hline & Neurological & $472(12.6)$ & $12,454(14.9)$ & \\
\hline & Musculoskeletal & $289(7.7)$ & $8489(10.2)$ & \\
\hline & Cardiovascular & $320(8.5)$ & $8068(9.6)$ & \\
\hline & Skin & $212(5.7)$ & $7633(9.1)$ & \\
\hline & ENT & $265(7.1)$ & $6698(8.0)$ & \\
\hline & Respiratory & $241(6.4)$ & $4312(5.2)$ & \\
\hline & Others & $429(11.5)$ & 9025 (10.8) & \\
\hline Severe disease, $n(\%)$ & & $336(9.0)$ & $5946(7.1)$ & $<0.0001$ \\
\hline Emergency physician, $n(\%)$ & & $1373(36.7)$ & $29,129(34.8)$ & 0.0205 \\
\hline \multirow[t]{4}{*}{ Area, $n(\%)$} & Monitoring area & $156(4.2)$ & $3101(3.7)$ & $<0.0001$ \\
\hline & Bed area & $722(19.3)$ & $11,158(13.3)$ & \\
\hline & Chair area & $1016(27.1)$ & $19,129(22.9)$ & \\
\hline & Fast track & $1849(49.4)$ & $50,229(60.1)$ & \\
\hline \multirow[t]{4}{*}{ Time of ED arrival, $n(\%)$} & $0-6$ & $758(20.3)$ & $16,328(19.5)$ & 0.0208 \\
\hline & $6-12$ & $1042(27.8)$ & $21,896(26.2)$ & \\
\hline & $12-18$ & $963(25.7)$ & $23,117(27.6)$ & \\
\hline & $18-24$ & $980(26.2)$ & $22,276(26.6)$ & \\
\hline Weekend, $n(\%)$ & & $1297(34.7)$ & $28,871(34.5)$ & 0.8763 \\
\hline \multirow[t]{4}{*}{ Season, $n(\%)$} & Spring & 1093 (29.2) & $23,931(28.6)$ & 0.0752 \\
\hline & Summer & $759(20.3)$ & $15,803(18.9)$ & \\
\hline & Autumn & $843(22.5)$ & $19,299(23.1)$ & \\
\hline & Winter & $1048(28.0)$ & $24,584(29.4)$ & \\
\hline Laboratory study, $n(\%)$ & & $2877(76.9)$ & $55,042(65.8)$ & $<0.0001$ \\
\hline \multirow[t]{3}{*}{ Imaging study, $n(\%)$} & X-ray & $2760(73.7)$ & $56,540(67.6)$ & $<0.0001$ \\
\hline & $\mathrm{CT}$ & $1163(31.1)$ & $24,500(29.3)$ & 0.0199 \\
\hline & MRI & $93(2.5)$ & $4095(4.9)$ & $<0.0001$ \\
\hline Specialty consultation, $n(\%)$ & & 2019 (53.9) & $38,453(46.0)$ & $<0.0001$ \\
\hline \multirow[t]{2}{*}{ Discharge type, $n(\%)$} & $\begin{array}{l}\text { Normal } \\
\text { discharge }\end{array}$ & 3415 (91.2) & $79,385(94.9)$ & $<0.0001$ \\
\hline & DAMA & $328(8.8)$ & $4232(5.1)$ & \\
\hline $\begin{array}{l}\text { ED arrival to area (min), median } \\
\text { (IQR) }\end{array}$ & & $13.1(7.9-21.0)$ & $13.7(8.4-21.7)$ & $<0.0001$ \\
\hline ED LOS (min), median (IQR) & & $\begin{array}{c}224.5 \\
(139.2-368.1)\end{array}$ & $\begin{array}{c}184.6 \\
(116.5-305.2)\end{array}$ & $<0.0001$ \\
\hline \multirow{9}{*}{ Overcrowding, $n(\%)$} & TF4h & $946(25.3)$ & $22,007(26.3)$ & 0.1553 \\
\hline & TF1h & $924(24.7)$ & $22,075(26.4)$ & 0.0198 \\
\hline & TL1h & $899(24.0)$ & $21,901(26.2)$ & 0.0030 \\
\hline & EF4h & $1140(30.5)$ & $27,265(32.6)$ & 0.0060 \\
\hline & EF1h & $1136(30.3)$ & $26,970(32.3)$ & 0.0147 \\
\hline & EL1h & $1101(29.4)$ & $26,327(31.5)$ & 0.0076 \\
\hline & BF4h & $757(20.2)$ & $15,856(19.0)$ & 0.0543 \\
\hline & BF1h & $777(20.8)$ & $16,195(19.4)$ & 0.0354 \\
\hline & BL1h & $729(19.5)$ & $15,804(18.9)$ & 0.3789 \\
\hline
\end{tabular}

$\mathrm{RV}$, return visit; EMS, emergency medical services; KTAS, Korean Triage and Acuity Scale; ENT, ears, nose and throat; ED, emergency department; CT, computed tomography; MRI, magnetic resonance imaging; DAMA, discharge against medical advice; IQR, interquartile range; LOS, length of stay; TF4h, total patients during first $4 \mathrm{~h}$; TF1h, total patients during first $1 \mathrm{~h}$; TL1h, total patients during last $1 \mathrm{~h}$; EF4h, evaluating patients during first $4 \mathrm{~h}$; EF1h, evaluating patients during first $1 \mathrm{~h}$; EL1h, evaluating patients during last $1 \mathrm{~h} ; \mathrm{BF} 4 \mathrm{~h}$, boarding patients during first $4 \mathrm{~h}$; BF1h, boarding patients during first $1 \mathrm{~h}$; BL1h, boarding patients during last $1 \mathrm{~h}$. 


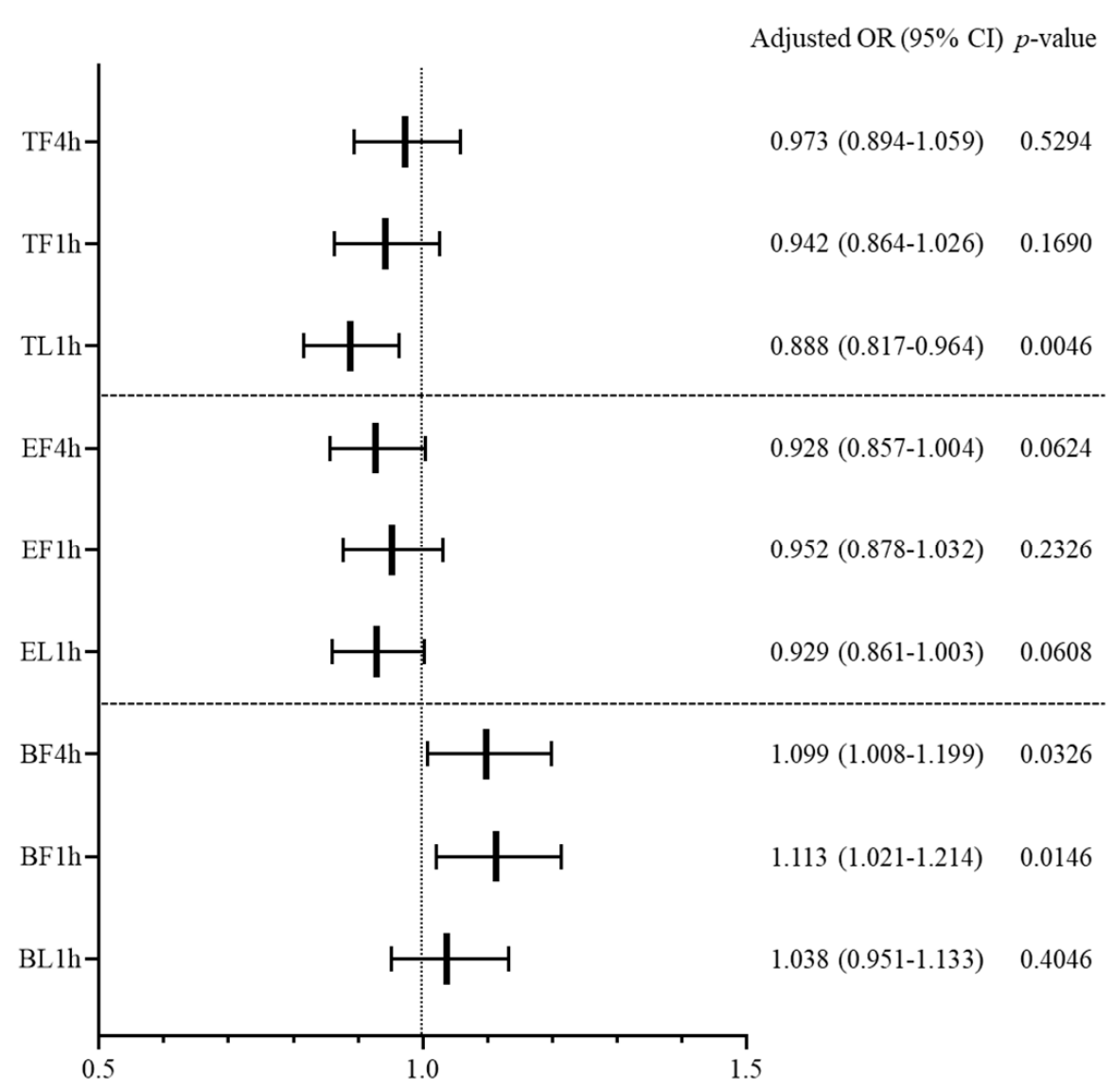

Figure 4. Influence of overcrowding in the emergency department on the occurrence of return visit within $72 \mathrm{~h}$. OR, odds ratio; CI, confidence interval; TF4h, total patients during first $4 \mathrm{~h}$; TF1h, total patients during first $1 \mathrm{~h}$; TL1h, total patients during last $1 \mathrm{~h}$; EF4h, evaluating patients during first $4 \mathrm{~h}$; EF1h, evaluating patients during first $1 \mathrm{~h}$; EL1h, evaluating patients during last $1 \mathrm{~h}$; BF4h, boarding patients during first $4 \mathrm{~h}$; BF1h, boarding patients during first $1 \mathrm{~h}$; BL1h, boarding patients during last $1 \mathrm{~h}$.

\subsection{Comparison between RVA and RVNA}

Table 2 compares the characteristics of patients with RVA and RVNA. In the RVA group, patients were older and there were more males $(51.4 \%$ vs. $44.0 \%, p<0.0001)$. There were more KTAS 2 and 3 in the RVA group, and more KTAS 4 and 5 in the RVNA group $(p<0.0001)$. In the RVA group, the proportion of non-medical problems was lower $(4.6 \%$ vs. $11.9 \%, p<0.0001)$, and more patients were diagnosed with severe disease $(15.2 \%$ vs. $6.3 \%, p<0.0001)$. Laboratory tests, imaging studies, and specialty consultations were carried out more frequently in the RVA group than in the RVNA group, and the ED LOS was longer in the RVA group (adjusted OR (95\% CI) 324.3 (196.2-479.0) min vs. 191.5 (123.4-314.1) min, $p<$ 0.0001). There was no significant difference between the two groups for crowding indicators related to total number of patients. In the evaluation indicators, EF4h and EL1h showed no significant difference, but EF1h was higher in RVA than in the RVNA group (33.7\% vs. 28.9\%, $p=0.0038)$. 
Table 2. Comparison of patient characteristics of index visits according to the treatment result of return visit.

\begin{tabular}{|c|c|c|c|c|}
\hline \multicolumn{2}{|l|}{ Variables } & \multirow{2}{*}{$\begin{array}{c}\text { RVA } \\
n=\mathbf{1 1 1 3}\end{array}$} & \multirow{2}{*}{$\begin{array}{c}\begin{array}{c}\text { RVNA } \\
n=2630\end{array} \\
847(32.2)\end{array}$} & \multirow{2}{*}{$\begin{array}{c}p \text {-Value } \\
<0.0001\end{array}$} \\
\hline Age, $n(\%)$ & -39 & & & \\
\hline & $40-64$ & $414(37.2)$ & $1001(38.1)$ & \\
\hline & $65-79$ & $333(29.9)$ & $562(21.4)$ & \\
\hline & $80-$ & $126(11.3)$ & $220(8.4)$ & \\
\hline Female, $n(\%)$ & & $541(48.6)$ & $1474(56.0)$ & $<0.0001$ \\
\hline Transfer in, $n(\%)$ & & $117(10.5)$ & $203(7.7)$ & 0.0052 \\
\hline EMS, $n(\%)$ & & $298(26.8)$ & $560(21.3)$ & 0.0003 \\
\hline \multirow[t]{5}{*}{ KTAS, $n(\%)$} & 1 & $2(0.2)$ & $4(0.2)$ & $<0.0001$ \\
\hline & 2 & $76(6.8)$ & $131(5.0)$ & \\
\hline & 3 & $324(29.1)$ & $473(18.0)$ & \\
\hline & 4 & $655(58.8)$ & $1622(61.7)$ & \\
\hline & 5 & $56(5.0)$ & $400(15.2)$ & \\
\hline Non-medical, $n(\%)$ & & $51(4.6)$ & $312(11.9)$ & $<0.0001$ \\
\hline \multirow[t]{9}{*}{ Complaint category, $n(\%)$} & Gastrointestinal & $324(29.1)$ & $489(18.6)$ & $<0.0001$ \\
\hline & General & $248(22.3)$ & $454(17.3)$ & \\
\hline & Neurological & $131(11.8)$ & $341(13.0)$ & \\
\hline & Cardiovascular & $83(7.5)$ & $237(9.0)$ & \\
\hline & Musculoskeletal & $61(5.5)$ & $228(8.7)$ & \\
\hline & ENT & $47(4.2)$ & $218(8.3)$ & \\
\hline & Respiratory & $105(9.4)$ & $136(5.2)$ & \\
\hline & Skin & $15(1.3)$ & $197(7.5)$ & \\
\hline & Others & $99(8.9)$ & $330(12.5)$ & \\
\hline Severe disease, $n(\%)$ & & $169(15.2)$ & $167(6.3)$ & $<0.0001$ \\
\hline Emergency physician, $n(\%)$ & & $474(42.6)$ & $899(34.2)$ & $<0.0001$ \\
\hline \multirow[t]{4}{*}{ Area, $n(\%)$} & Monitoring area & $71(6.4)$ & $85(3.2)$ & $<0.0001$ \\
\hline & Bed area & $312(28.0)$ & $410(15.6)$ & \\
\hline & Chair area & $334(30.0)$ & $682(25.9)$ & \\
\hline & Fast track & $396(35.6)$ & $1453(55.2)$ & \\
\hline \multirow[t]{4}{*}{ Time of ED arrival, $n(\%)$} & $0-6$ & $196(17.6)$ & $562(21.4)$ & 0.0384 \\
\hline & $6-12$ & $331(29.7)$ & $711(27.0)$ & \\
\hline & $12-18$ & $299(26.9)$ & $664(25.2)$ & \\
\hline & $18-24$ & $287(25.8)$ & $693(26.3)$ & \\
\hline Weekend, $n(\%)$ & & $396(35.6)$ & $901(34.3)$ & 0.4376 \\
\hline \multirow[t]{4}{*}{ Season, $n(\%)$} & Spring & $323(29.0)$ & $770(29.3)$ & 0.9808 \\
\hline & Summer & $228(20.5)$ & $531(20.2)$ & \\
\hline & Autumn & $247(22.2)$ & $596(22.7)$ & \\
\hline & Winter & $315(28.3)$ & $733(27.9)$ & \\
\hline Laboratory study, $n(\%)$ & & $1002(90.0)$ & $1875(71.3)$ & $<0.0001$ \\
\hline \multirow[t]{3}{*}{ Imaging study, $n(\%)$} & X-ray & $958(86.1)$ & $1802(68.5)$ & $<0.0001$ \\
\hline & $\mathrm{CT}$ & $447(40.2)$ & $716(27.2)$ & $<0.0001$ \\
\hline & MRI & $37(3.3)$ & $56(2.1)$ & 0.0318 \\
\hline Specialty consultation, $n(\%)$ & & $784(70.4)$ & $1235(47.0)$ & $<0.0001$ \\
\hline \multirow[t]{2}{*}{ Discharge type, $n(\%)$} & $\begin{array}{l}\text { Normal } \\
\text { discharge }\end{array}$ & $980(88.1)$ & $2435(92.6)$ & $<0.0001$ \\
\hline & DAMA & $133(11.9)$ & $195(7.4)$ & \\
\hline $\begin{array}{l}\text { ED arrival to area (min), median } \\
\text { (IQR) }\end{array}$ & & $13.2(7.5-21.7)$ & $13.1(8.1-20.6)$ & 0.9295 \\
\hline ED LOS (min), median (IQR) & & $\begin{array}{c}324.3 \\
(196.2-479.0)\end{array}$ & $\begin{array}{c}191.5 \\
(123.4-314.1)\end{array}$ & $<0.0001$ \\
\hline \multirow{9}{*}{ Overcrowding, $n(\%)$} & TF4h & $304(27.3)$ & $642(24.4)$ & 0.0618 \\
\hline & TF1h & $298(26.8)$ & $626(23.8)$ & 0.0539 \\
\hline & TL1h & $270(24.3)$ & $629(23.9)$ & 0.8226 \\
\hline & EF4h & $358(32.2)$ & $782(29.7)$ & 0.1396 \\
\hline & EF1h & $375(33.7)$ & $761(28.9)$ & 0.0038 \\
\hline & EL1h & $324(29.1)$ & 777 (29.5) & 0.7903 \\
\hline & BF4h & $225(20.2)$ & $532(20.2)$ & 0.9931 \\
\hline & BF1h & $234(21.0)$ & $543(20.6)$ & 0.7944 \\
\hline & BL1h & $226(20.3)$ & $503(19.1)$ & 0.4047 \\
\hline
\end{tabular}

RVA, return visit with admission; RVNA, return visit with no admission; EMS, emergency medical services; KTAS, Korean Triage and Acuity Scale; ENT, ears, nose and throat; ED, emergency department; CT, computed tomography; MRI, magnetic resonance imaging; DAMA, discharge against medical advice; IQR, interquartile range; LOS, length of stay; TF4h, total patients during first $4 \mathrm{~h}$; TF1h, total patients during first $1 \mathrm{~h}$; TL1h, total patients during last $1 \mathrm{~h}$; EF4h, evaluating patients during first $4 \mathrm{~h}$; EF1h, evaluating patients during first $1 \mathrm{~h}$; EL1h, evaluating patients during last $1 \mathrm{~h}$; BF4h, boarding patients during first $4 \mathrm{~h}$; BF1h, boarding patients during first $1 \mathrm{~h}$; BL1h, boarding patients during last $1 \mathrm{~h}$. 


\subsection{Influence of ED Overcrowding on RVA Occurrence}

Multivariable logistic regression was conducted to determine whether overcrowding indicators affected RVA occurrence (Figure 5). Among the crowding indicators of total patients, TF4h and TF1h were found to increase RVA incidence (adjusted OR (95\% CI) 1.239 (1.017-1.510), $p=0.0335$ for TF4h; 1.278 (1.046-1.562), $p=0.0166$ for TF1h). Among evaluating indicators, EF1h was found to have a significant effect on RVA (adjusted OR (95\% CI) 1.296 (1.078-1.559), $p=0.0059)$. None of the crowding indicators with regard to boarding patients had a significant effect on RVA. Other factors influencing RVA occurrence were age, sex, non-medical problem, complaint category, severe disease, treatment area, laboratory study, CT evaluation, specialty consultation, DAMA, and ED LOS. The univariable logistic regression results are presented in Appendix $\mathrm{E}$, and the results of multivariable logistic regression of each crowding indicator are added as Appendices F-H.

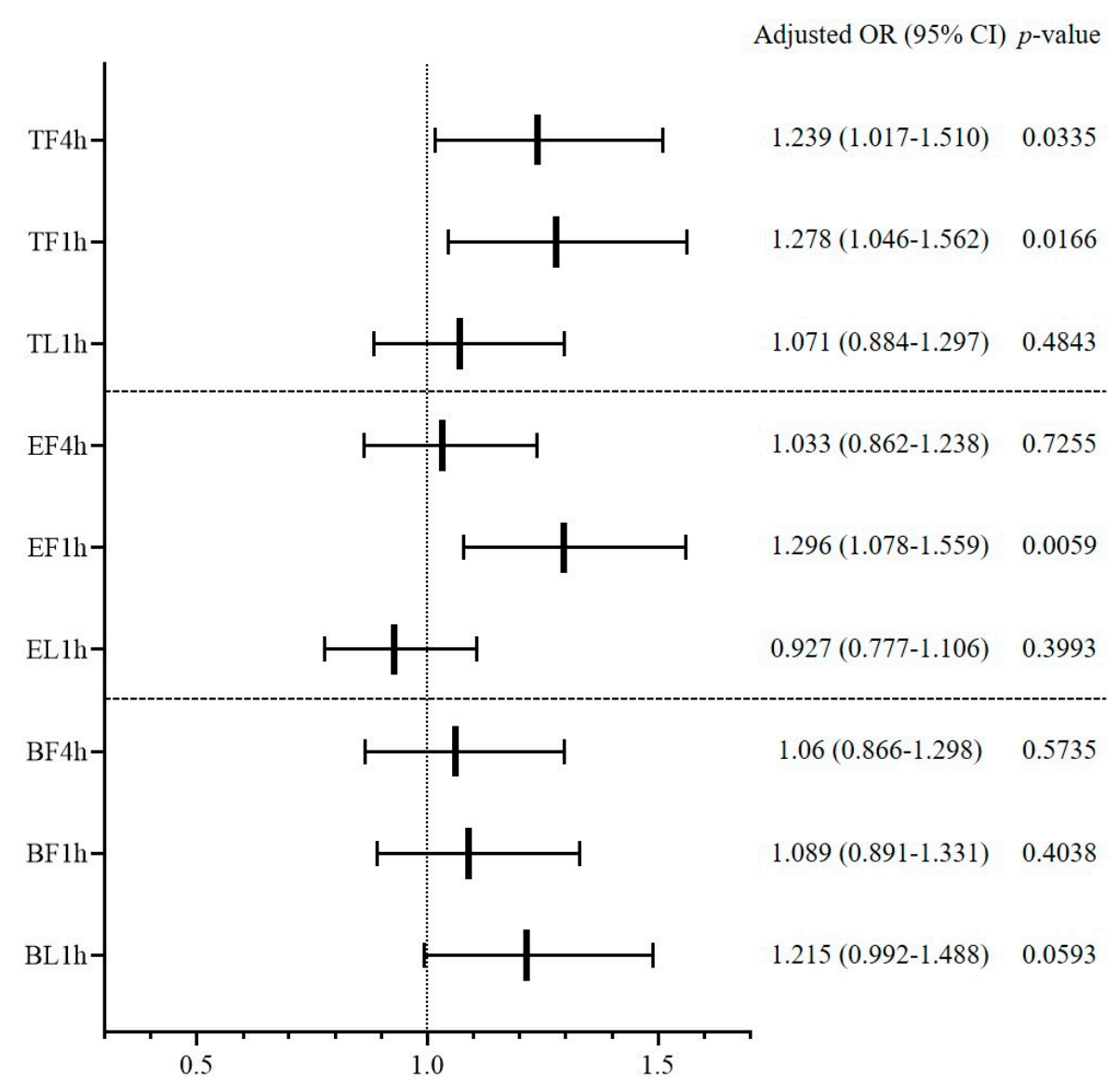

Figure 5. Influence of overcrowding in the emergency department on the occurrence of return visit with admission within $72 \mathrm{~h}$. OR, odds ratio; CI, confidence interval; TF4h, total patients during first $4 \mathrm{~h}$; TF1h, total patients during first $1 \mathrm{~h}$; TL1h, total patients during last $1 \mathrm{~h}$; EF4h, evaluating patients during first $4 \mathrm{~h}$; EF1h, evaluating patients during first $1 \mathrm{~h}$; EL1h, evaluating patients during last $1 \mathrm{~h}$; BF4h, boarding patients during first $4 \mathrm{~h}$; BF1h, boarding patients during first $1 \mathrm{~h}$; BL1h, boarding patients during last $1 \mathrm{~h}$.

\section{Discussion}

In this study, $4.3 \%$ of discharged patients returned to the ED within $72 \mathrm{~h}$, which is within $2.7-6.5 \%$ of the $72 \mathrm{~h} \mathrm{RV}$ rate that was previously reported [8,23-25]. Being male and an older adult, as well as having visits due to medical problems, were factors that increased RV, and among complaint categories, the gastrointestinal category was also a significant factor for increased RV. Previous studies examining the characteristics of RV patients have commonly reported abdominal pain as the most 
common cause of RV $[23,24,26,27]$. The factor of ED overcrowding that increased the occurrence of $\mathrm{RV}$ was the number of boarding patients rather than the total number of patients. Boarding patients exceeding the third quartile was associated with a 10\% higher risk of RV. Accumulation of boarding patients in the ED implies that the ED output is blocked, which is directly affected by the in-hospital bed occupancy $[28,29]$. If the inpatient occupancy rate is too high and the ED is overcrowded with boarding patients awaiting hospital beds, emergency doctors become more careful when making a decision for additional admissions and decide to transfer some patients to other hospitals or plan discharge and short-term follow-up for patients with relatively mild conditions [30-32]. Previous studies have reported that high in-hospital bed occupancy reduced the number of patients admitted through the ED [31,33]. Therefore, this reduced scope of admission would probably increase the possibility of RV by increasing the risk of inadequate or premature discharge. However, one study that investigated whether inpatient occupancy affected the $72 \mathrm{~h}$ RV rate of ED reported results that were not significant [11]. The hospital of Sweden where the abovementioned study was conducted has a strategy to facilitate the output of the ED; the Swedish government restricts the time spent in the emergency room to $4 \mathrm{~h}$, and the hospital operates a full-capacity protocol when the inpatient bed-occupancy rate reaches $100 \%$ [11]. The government's policy to limit the ED LOS brings about changes in the hospital system that facilitates patient flow [34], and the full-capacity protocol that hospitalizes boarding patients of the ED into the corridor of hospital wards in overcrowded situation is effective in resolving ED overcrowding $[35,36]$. However, the Korean government is not adopting this potent policy, and most Korean hospitals, including ours, do not have effective hospital-wide action plans against overcrowding; therefore, medical staff in the ED must struggle with the burden of hospital overcrowding at their own individual strengths. We found that the number of boarding patients increased the occurrence of RV, reflecting greater pressure of the ED output blockage on emergency physicians in our ED. Operating an aftercare service for a high-risk patients discharged home when the ED output is blocked may help reduce RV.

An interesting and unexpected result in this study was that excessive numbers of total patients at the time of ED departure of index visit reduced RV occurrence. However, this reverse correlation between ED overcrowding and RV can be found in the results of McCusker et al.'s study [37]. The patient's discharge process in the ED is an important step in explaining the patient's condition and examination results, giving the patient confidence in the doctor's discharge decision, and educating post-discharge precautions [38-40]. However, ED overcrowding shortens the time for the doctor to communicate with the patient; doctors may find it difficult to invest sufficient time to explain discharge instructions to the patient in situations where more patients need to be cared for $[38,41]$. If the discharge process progresses hastily, the patient may not adequately understand post-discharge instructions, which may lead to increased RV, but may also make the patient less likely to come to the ED again by reducing patient satisfaction $[42,43]$. This is consistent with the perspective that ED visitors are potential consumers of the hospital in the marketing aspect of medical services, and satisfaction in the ED affects the perception of the quality of medical services of the hospital, thereby improving customer loyalty and continuing to use their services [44,45]. A study analyzing the State Emergency Department Databases (SEDD) of six states in the United States reported that 32\% of RV patients returned to the ED of another hospital rather than the one at the first visit [6]. The patient's deterioration in satisfaction due to ED overcrowding can be a factor in choosing other hospitals when additional medical treatment is needed - that is, reducing the RV to our ED. It is necessary to further conduct regional multicenter research on patients who choose other hospitals when they return to the ED.

The entire $72 \mathrm{~h}$ RV rate has been most commonly used for monitoring ED performance [4,5,21,23], but many of the RVs are caused by patient factors such as worry about health, or illness factors such as disease progression, rather than medical error $[1,9,20,23]$, and several researchers suggested that the rate of RVA may be a better indicator for reflecting the quality of healthcare $[3,46]$. In this study, the $72 \mathrm{~h}$ RVA rate was $0.9 \%$ of total ED visits, similar to the $0.5-1.5 \%$ reported in previous studies $[1,11,20]$. The proportion of RVA in total RV was $29.7 \%$, which was higher than the admission rate of $24.0 \%$ in all 
ED patients. In the previous study, the admission rate of patients who returned to the ED within $72 \mathrm{~h}$ has been variously reported as $8.2-46.1 \%[3,5,19,20]$. A common risk factor for RVA in previous studies was being aged $\geq 65$ years, which was also confirmed in our study $[8,20]$. ED overcrowding, especially at the arrival time of index visit, was a significant factor causing RVA rather than RVNA. A study focusing on the adverse outcome of ED overcrowding also noted a small but significant increase in RVA as the ED occupancy increased [37]. However, two studies on the subject of disposition after RV did not confirm the significant effect of crowding on admission, which may be due to differences from our study in the definition of overcrowding [8,20]. Hu et al. used the ED census during the shift of the index visit [8], and Hayward et al. applied the ED occupancy level at the triage of the index visit as a continuous variable [20]. In McCarthy et al.'s study on the method of measuring ED crowding, crowding measured at the daily level masked most of the crowding variations that occurred within $24 \mathrm{~h}$, and ED census on arrival revealed more variations in crowding compared to the average ED census during the shift [47]. We were able to confirm that the ED overcrowding is a factor that increases the occurrence of RVA by setting an influential indicator of excessive number of patients over the critical level at the time of ED arrival of the index visit. When the level of overcrowding exceeds the critical threshold, additional manpower and resources should be provided to ensure patient safety. Additionally, a system for prompt and accurate decision-making, such as early physician assessment and physician-led triage, will help prevent RV as well as alleviate ED crowding through improved patient flow [48].

\section{Limitation}

This study had some limitations. First, as this study was conducted in a single hospital, patients who returned to other hospitals after discharge from our ED were not included. Actual revisit rates could be higher than detected, and patients who chose other hospitals may have different characteristics, which may have caused selection bias. Second, this ED belongs to a tertiary university hospital, which is located in the capital city of South Korea and has a high bed-occupancy rate and large number of patients waiting for admission. Therefore, care is warranted when seeking to generalize our results to other hospitals or countries. Third, we defined overcrowding simply on the basis of the number of occupying patients, and the difficulty of treatment or the severity of the disease of occupying patients was not taken into account. Even the same number of patients may differ in regards to burden on medical staff depending on the characteristics of the patient. Therefore, further research is needed to apply overcrowding criteria that can more accurately judge the actual overload of medical staff. Lastly, as a drawback of the retrospective study design, we could not investigate the cause of RV. In order to understand why ED overcrowding affects RV, it is necessary to look into the effect of overcrowding by the category of the cause of RV.

\section{Conclusions}

The occurrence of RV depends on ED overcrowding defined by the number of boarding patients above the third quartile. A higher number of patients occupying the ED above the third quartile at the arrival time of the index visit appeared to increase the likelihood of admission when the patient returned to the ED. However, excessive patient load when leaving the ED was associated with reduced incidence of RV. In order to understand the mechanism of this phenomenon, it would be helpful to analyze the reasons of RV together.

Author Contributions: Conceptualization, M.J.K. and D.-u.K.; methodology, M.J.K.; software, J.M.P.; validation, N.J.B. and K.C.; formal analysis, M.J.K.; investigation, J.H.K.; resources, J.H.L.; data curation, J.M.P.; writing-original draft preparation, M.J.K. and D.-u.K.; writing-review and editing, J.M.P.; visualization, M.J.K. and D.-u.K.; supervision, Y.S.P.; project administration, N.J.B, and K.C.; funding acquisition, M.J.K. All authors have read and agreed to the published version of the manuscript.

Funding: This work was supported by the National Research Foundation of Korea (NRF) grant funded by the Korea government (Ministry of Science and ICT) (No. 2017R1C1B5076958).

Conflicts of Interest: The authors declare no conflict of interest. 


\section{Appendix A}

Table A1. Univariable logistic regression of emergency department overcrowding for return visit within $72 \mathrm{~h}$.

\begin{tabular}{|c|c|c|c|}
\hline \multicolumn{2}{|c|}{ Variable. } & \multirow{2}{*}{$\begin{array}{c}\text { Odds Ratio }(95 \% \mathrm{CI}) \\
1\end{array}$} & \multirow[t]{2}{*}{$p$-Value } \\
\hline Age & -39 & & \\
\hline & $40-64$ & 1.455 (1.343-1.578) & $<0.0001$ \\
\hline & $65-79$ & $1.698(1.551-1.859)$ & $<0.0001$ \\
\hline & $80-$ & $2.051(1.811-2.323)$ & $<0.0001$ \\
\hline Female & & $0.888(0.831-0.948)$ & 0.0004 \\
\hline Transfer in & & $1.053(0.937-1.184)$ & 0.3876 \\
\hline EMS & & $1.279(1.182-1.383)$ & $<0.0001$ \\
\hline \multirow[t]{5}{*}{ KTAS } & 1 & 1 & \\
\hline & 2 & $1.730(0.760-3.938)$ & 0.1914 \\
\hline & 3 & $1.925(0.853-4.343)$ & 0.1146 \\
\hline & 4 & $1.776(0.789-3.999)$ & 0.1654 \\
\hline & 5 & $1.235(0.546-2.793)$ & 0.6119 \\
\hline Non-medical & & $0.372(0.334-0.415)$ & $<0.0001$ \\
\hline \multirow[t]{9}{*}{ Complaint category } & Gastrointestinal & 1 & \\
\hline & General & $1.006(0.907-1.116)$ & 0.9054 \\
\hline & Neurological & $0.676(0.602-0.759)$ & $<0.0001$ \\
\hline & Musculoskeletal & $0.607(0.529-0.696)$ & $<0.0001$ \\
\hline & Cardiovascular & $0.707(0.620-0.807)$ & $<0.0001$ \\
\hline & Skin & $0.495(0.425-0.578)$ & $<0.0001$ \\
\hline & ENT & $0.706(0.612-0.813)$ & $<0.0001$ \\
\hline & Respiratory & $0.997(0.860-1.155)$ & 0.9648 \\
\hline & Others & $0.848(0.752-0.956)$ & 0.0069 \\
\hline Severe disease & & 1.289 (1.149-1.446) & $<0.0001$ \\
\hline Emergency physician & & $1.084(1.012-1.160)$ & 0.0205 \\
\hline \multirow{4}{*}{ Area } & Monitoring area & 1 & \\
\hline & Bed area & $1.286(1.077-1.536)$ & 0.0055 \\
\hline & Chair area & $1.056(0.888-1.255)$ & 0.5379 \\
\hline & Fast track & $0.732(0.619-0.865)$ & 0.0003 \\
\hline \multirow[t]{4}{*}{ Time of ED arrival } & $0-6$ & 1 & \\
\hline & $6-12$ & $1.025(0.932-1.128)$ & 0.6118 \\
\hline & $12-18$ & $0.897(0.814-0.989)$ & 0.0290 \\
\hline & $18-24$ & $0.948(0.860-1.044)$ & 0.2770 \\
\hline Weekend & & 1.005 (0.939-1.077) & 0.8762 \\
\hline \multirow[t]{4}{*}{ Season } & Spring & 1 & \\
\hline & Summer & $1.052(0.957-1.156)$ & 0.2982 \\
\hline & Autumn & $0.956(0.872-1.048)$ & 0.3412 \\
\hline & Winter & $0.933(0.856-1.018)$ & 0.1185 \\
\hline Laboratory study & & $1.725(1.596-1.863)$ & $<0.0001$ \\
\hline \multirow[t]{3}{*}{ Imaging study } & X-ray & $1.344(1.248-1.448)$ & $<0.0001$ \\
\hline & $\mathrm{CT}$ & $1.088(1.013-1.168)$ & 0.0200 \\
\hline & MRI & $0.495(0.402-0.609)$ & $<0.0001$ \\
\hline Specialty consultation & & 1.376 (1.288-1.469) & $<0.0001$ \\
\hline Discharge type & DAMA & $1.802(1.602-2.026)$ & $<0.0001$ \\
\hline ED arrival to area & & $0.930(0.832-1.040)$ & 0.2012 \\
\hline ED LOS & & $1.018(1.014-1.023)$ & $<0.0001$ \\
\hline \multirow{9}{*}{ Overcrowding } & TF4h & $0.947(0.878-1.021)$ & 0.1553 \\
\hline & TF1h & $0.914(0.847-0.986)$ & 0.0199 \\
\hline & TL1h & $0.891(0.825-0.962)$ & 0.0031 \\
\hline & EF4h & & \\
\hline & EF1h & & \\
\hline & EL1h & & \\
\hline & BF4h & $1.083(0.999-1.176)$ & 0.0543 \\
\hline & BF1h & $1.091(1.006-1.182)$ & 0.0354 \\
\hline & BL1h & $1.038(0.956-1.128)$ & 0.3738 \\
\hline
\end{tabular}

CI, confidence interval; EMS, emergency medical services; KTAS, Korean Triage and Acuity Scale; ENT, ears, nose and throat; ED, emergency department; CT, computed tomography; MRI, magnetic resonance imaging; DAMA, discharge against medical advice; LOS, length of stay; TF4h, total patients during first $4 \mathrm{~h}$; TF1h, total patients during first $1 \mathrm{~h}$; TL1h, total patients during last $1 \mathrm{~h}$; EF4h, evaluating patients during first $4 \mathrm{~h}$; EF1h, evaluating patients during first $1 \mathrm{~h}$; EL1h, evaluating patients during last $1 \mathrm{~h}$; BF4h, boarding patients during first $4 \mathrm{~h}$; BF1h, boarding patients during first $1 \mathrm{~h}$; BL1h, boarding patients during last $1 \mathrm{~h}$. 


\section{Appendix B}

Table A2. Multivariable logistic regression of emergency department overcrowding of the number of total patients for return visit within $72 \mathrm{~h}$.

\begin{tabular}{|c|c|c|c|c|c|c|c|}
\hline \multirow{2}{*}{\multicolumn{2}{|c|}{ Variables }} & \multicolumn{2}{|l|}{ TF4h } & \multicolumn{2}{|l|}{ TF1h } & \multicolumn{2}{|l|}{ TL1h } \\
\hline & & Odds Ratio (95\% CI) & $p$-Value & Odds Ratio (95\% CI) & $p$-Value & Odds Ratio (95\% CI) & $p$-Value \\
\hline \multirow[t]{4}{*}{ Age } & -39 & 1 & & 1 & & 1 & \\
\hline & $40-64$ & $1.332(1.226-1.448)$ & $<0.0001$ & $1.333(1.226-1.448)$ & $<0.0001$ & $1.334(1.228-1.450)$ & $<0.0001$ \\
\hline & $65-79$ & $1.473(1.338-1.623)$ & $<0.0001$ & $1.475(1.339-1.624)$ & $<0.0001$ & $1.477(1.341-1.628)$ & $<0.0001$ \\
\hline & $80-$ & $1.713(1.500-1.956)$ & $<0.0001$ & $1.715(1.502-1.959)$ & $<0.0001$ & $1.719(1.505-1.962)$ & $<0.0001$ \\
\hline Female & & $0.910(0.851-0.973)$ & 0.0058 & $0.910(0.851-0.973)$ & 0.0058 & $0.910(0.851-0.973)$ & 0.0058 \\
\hline EMS & & $1.119(1.023-1.224)$ & 0.0142 & $1.119(1.023-1.224)$ & 0.0142 & $1.119(1.023-1.224)$ & 0.0139 \\
\hline Non-medical & & $0.338(0.341-0.441)$ & $<0.0001$ & $0.387(0.340-0.440)$ & $<0.0001$ & $0.387(0.340-0.440)$ & $<0.0001$ \\
\hline \multirow[t]{9}{*}{ Complaint category } & Gastrointestinal & 1 & & 1 & & 1 & \\
\hline & General & $1.053(0.947-1.172)$ & 0.3375 & $1.053(0.947-1.171)$ & 0.3433 & $1.052(0.946-1.170)$ & 0.3505 \\
\hline & Neurological & $0.797(0.701-0.906)$ & 0.0005 & $0.797(0.701-0.906)$ & 0.0005 & $0.797(0.701-0.906)$ & 0.0005 \\
\hline & Musculoskeletal & $0.984(0.847-1.143)$ & 0.8327 & $0.983(0.846-1.141)$ & 0.8201 & $0.983(0.847-1.142)$ & 0.8243 \\
\hline & Cardiovascular & $0.614(0.536-0.704)$ & $<0.0001$ & $0.614(0.536-0.704)$ & $<0.0001$ & $0.615(0.537-0.704)$ & $<0.0001$ \\
\hline & Skin & $0.856(0.724-1.013)$ & 0.0711 & $0.855(0.722-1.011)$ & 0.0674 & $0.853(0.721-1.010)$ & 0.0646 \\
\hline & ENT & $0.954(0.818-1.113)$ & 0.5503 & $0.952(0.816-1.111)$ & 0.5293 & $0.949(0.814-1.108)$ & 0.5085 \\
\hline & Respiratory & $0.831(0.714-0.966)$ & 0.0162 & $0.830(0.714-0.966)$ & 0.0161 & $0.830(0.714-0.966)$ & 0.0161 \\
\hline & Others & $0.902(0.794-1.026)$ & 0.1163 & $0.901(0.793-1.024)$ & 0.1109 & $0.900(0.791-1.023)$ & 0.1061 \\
\hline Severe disease & & $0.906(0.802-1.025)$ & 0.1166 & $0.907(0.802-1.025)$ & 0.1176 & $0.907(0.802-1.025)$ & 0.1187 \\
\hline Emergency physician & & $0.987(0.911-1.069)$ & 0.7417 & $0.989(0.913-1.071)$ & 0.7787 & $0.997(0.920-1.080)$ & 0.9396 \\
\hline \multirow{4}{*}{ Area } & Monitoring area & 1 & & 1 & & 1 & \\
\hline & Bed area & $1.198(0.998-1.438)$ & 0.0522 & $1.196(0.996-1.436)$ & 0.0547 & $1.195(0.995-1.434)$ & 0.0560 \\
\hline & Chair area & $1.076(0.892-1.298)$ & 0.4442 & $1.071(0.888-1.292)$ & 0.4744 & $1.070(0.887-1.290)$ & 0.4818 \\
\hline & Fast track & $0.953(0.792-1.148)$ & 0.6143 & $0.960(0.797-1.156)$ & 0.6657 & $0.968(0.804-1.165)$ & 0.7303 \\
\hline \multirow[t]{4}{*}{ Time of ED arrival } & $0-6$ & 1 & & 1 & & 1 & \\
\hline & $6-12$ & $0.910(0.820-1.010)$ & 0.0757 & $0.908(0.819-1.007)$ & 0.0676 & $0.926(0.834-1.028)$ & 0.1484 \\
\hline & $12-18$ & $0.850(0.762-0.948)$ & 0.0034 & $0.857(0.768-0.956)$ & 0.0056 & $0.856(0.768-0.953)$ & 0.0047 \\
\hline & $18-24$ & $0.959(0.868-1.059)$ & 0.4063 & $0.963(0.872-1.064)$ & 0.4619 & $0.958(0.867-1.058)$ & 0.3973 \\
\hline Laboratory study & & $1.091(0.975-1.221)$ & 0.1273 & $1.094(0.977-1.224)$ & 0.1186 & $1.094(0.978-1.224)$ & 0.1161 \\
\hline \multirow[t]{3}{*}{ Imaging study } & X-ray & $1.037(0.935-1.149)$ & 0.4920 & $1.038(0.936-1.151)$ & 0.4790 & $1.038(0.936-1.151)$ & 0.4776 \\
\hline & $\mathrm{CT}$ & $1.036(0.956-1.123)$ & 0.3897 & $1.036(0.956-1.123)$ & 0.3885 & $1.034(0.954-1.121)$ & 0.4108 \\
\hline & MRI & $0.403(0.322-0.504)$ & $<0.0001$ & $0.403(0.322-0.504)$ & $<0.0001$ & $0.401(0.320-0.502)$ & $<0.0001$ \\
\hline \multirow{2}{*}{$\begin{array}{l}\text { Specialty consultation } \\
\text { Discharge type }\end{array}$} & & $1.297(1.204-1.398)$ & $<0.0001$ & $1.297(1.204-1.398)$ & $<0.0001$ & $1.296(1.203-1.396)$ & $<0.0001$ \\
\hline & DAMA & $1.807(1.600-2.041)$ & $<0.0001$ & $1.809(1.601-2.043)$ & $<0.0001$ & $1.813(1.605-2.048)$ & $<0.0001$ \\
\hline & & $1.002(0.995-1.008)$ & 0.6045 & $1.002(0.995-1.008)$ & 0.5665 & $1.002(0.996-1.009)$ & 0.4937 \\
\hline \multirow{3}{*}{ Overcrowding } & TF4h & $0.973(0.894-1.059)$ & 0.5294 & & & & \\
\hline & TF1h & & & $0.942(0.864-1.026)$ & 0.1690 & & \\
\hline & TL1h & & & & & $0.888(0.817-0.964)$ & 0.0046 \\
\hline
\end{tabular}

TF4h, total patients during first $4 \mathrm{~h}$; TF1h, total patients during first $1 \mathrm{~h}$; TL1h, total patients during last $1 \mathrm{~h}$; CI, confidence interval; EMS, emergency medical services; ENT, ears, nose and throat; ED, emergency department; CT, computed tomography; MRI, magnetic resonance imaging; DAMA, discharge against medical advice; LOS, length of stay. 


\section{Appendix C}

Table A3. Multivariable logistic regression of emergency department overcrowding of the number of evaluating patients for return visit within $72 \mathrm{~h}$

\begin{tabular}{|c|c|c|c|c|c|c|c|}
\hline \multirow{2}{*}{\multicolumn{2}{|c|}{ Variables }} & \multicolumn{2}{|l|}{ EF4h } & \multicolumn{2}{|l|}{ EF1h } & \multicolumn{2}{|l|}{ EL1h } \\
\hline & & Odds Ratio $(95 \%$ CI $)$ & $p$-Value & Odds Ratio $(95 \%$ CI $)$ & $p$-Value & Odds Ratio $(95 \% \mathrm{CI})$ & $p$-Value \\
\hline \multirow{3}{*}{ Age } & -39 & 1 & & 1 & & 1 & \\
\hline & $40-64$ & $1.332(1.225-1.447)$ & $<0.0001$ & $1.332(1.225-1.447)$ & $<0.0001$ & $1.331(1.225-1.446)$ & $<0.0001$ \\
\hline & $80-$ & $1.711(1.498-1.953)$ & $<0.0001$ & $1.711(1.499-1.954)$ & $<0.0001$ & $1.711(1.499-1.954)$ & $<0.0001$ \\
\hline Female & & $0.910(0.852-0.973)$ & 0.0060 & $0.910(0.852-0.973)$ & 0.0059 & $0.910(0.851-0.973)$ & 0.0059 \\
\hline EMS & & $1.118(1.022-1.223)$ & 0.0150 & $1.118(1.022-1.223)$ & 0.0146 & $1.118(1.022-1.223)$ & 0.0147 \\
\hline Non-medical & & $0.387(0.341-0.441)$ & $<0.0001$ & $0.388(0.341-0.441)$ & $<0.0001$ & $0.388(0.341-0.441)$ & $<0.0001$ \\
\hline \multirow{6}{*}{ Complaint category } & Musculoskeletal & $1.054(0.948-1.172)$ & 0.3320 & $1.054(0.948-1.172)$ & 0.3329 & $1.054(0.948-1.172)$ & 0.3338 \\
\hline & Cardiovascular & $0.985(0.848-1.144)$ & 0.8407 & $0.984(0.848-1.143)$ & 0.8359 & $0.985(0.848-1.144)$ & 0.8457 \\
\hline & Skin & $0.797(0.701-0.906)$ & 0.0005 & $0.797(0.702-0.906)$ & 0.0005 & $0.799(0.703-0.908)$ & 0.0006 \\
\hline & ENT & $0.902(0.794-1.026)$ & 0.1157 & $0.903(0.794-1.026)$ & 0.1175 & $0.904(0.795-1.027)$ & 0.1215 \\
\hline & Respiratory & $0.831(0.714-0.967)$ & 0.0164 & $0.831(0.714-0.967)$ & 0.0164 & $0.830(0.714-0.966)$ & 0.0160 \\
\hline & Others & $0.857(0.724-1.015)$ & 0.0733 & $0.857(0.724-1.014)$ & 0.0731 & $0.858(0.725-1.015)$ & 0.0748 \\
\hline Severe disease & & $0.905(0.801-1.024)$ & 0.1122 & $0.906(0.801-1.024)$ & 0.1134 & $0.906(0.801-1.024)$ & 0.1132 \\
\hline \multirow[t]{4}{*}{ Time of ED arrival } & $0-6$ & 1 & & 1 & & 1 & \\
\hline & $6-12$ & $0.919(0.828-1.020)$ & 0.1134 & $0.909(0.819-1.008)$ & 0.0701 & $0.928(0.835-1.032)$ & 0.1684 \\
\hline & $12-18$ & $0.875(0.781-0.981)$ & 0.0218 & $0.864(0.771-0.967)$ & 0.0111 & $0.868(0.777-0.970)$ & 0.0125 \\
\hline & $18-24$ & $0.977(0.883-1.082)$ & 0.6598 & $0.972(0.877-1.078)$ & 0.5945 & $0.968(0.875-1.069)$ & 0.5184 \\
\hline Laboratory study & & $1.090(0.975-1.220)$ & 0.1311 & $1.091(0.975-1.220)$ & 0.1303 & $1.089(0.973-1.218)$ & 0.1375 \\
\hline \multirow[t]{3}{*}{ Imaging study } & X-ray & $1.038(0.936-1.150)$ & 0.4821 & $1.037(0.936-1.150)$ & 0.4863 & $1.037(0.935-1.149)$ & 0.4902 \\
\hline & $\mathrm{CT}$ & $1.036(0.956-1.122)$ & 0.3897 & $1.036(0.956-1.122)$ & 0.3934 & $1.035(0.955-1.121)$ & 0.4056 \\
\hline & MRI & $0.402(0.322-0.503)$ & $<0.0001$ & $0.403(0.322-0.504)$ & $<0.0001$ & $0.402(0.321-0.503)$ & $<0.0001$ \\
\hline Specialty consultation & & $1.298(1.204-1.398)$ & $<0.0001$ & $1.297(1.204-1.398)$ & $<0.0001$ & $1.298(1.205-1.399)$ & $<0.0001$ \\
\hline Discharge type & DAMA & $1.810(1.603-2.045)$ & $<0.0001$ & $1.808(1.601-2.042)$ & $<0.0001$ & 1.809 (1.601-2.043) & $<0.0001$ \\
\hline & & $1.002(0.995-1.008)$ & 0.5750 & $1.002(0.995-1.008)$ & 0.5971 & $1.002(0.995-1.008)$ & 0.6427 \\
\hline \multirow[t]{3}{*}{ Overcrowding } & EF4h & $0.928(0.857-1.004)$ & 0.0624 & & & & \\
\hline & EF1h & & & $0.952(0.878-1.032)$ & 0.2326 & & \\
\hline & EL1h & & & & & $0.929(0.861-1.003)$ & 0.0608 \\
\hline
\end{tabular}

EF4h, evaluating patients during first $4 \mathrm{~h}$; EF1h, evaluating patients during first $1 \mathrm{~h}$; EL1h, evaluating patients during last $1 \mathrm{~h}$; CI, confidence interval; EMS, emergency medical services; ENT, ears, nose and throat; ED, emergency department; CT, computed tomography; MRI, magnetic resonance imaging; DAMA, discharge against medical advice; LOS, length of stay. 


\section{Appendix D}

Table A4. Multivariable logistic regression of emergency department overcrowding of the number of boarding patients for return visit within $72 \mathrm{~h}$.

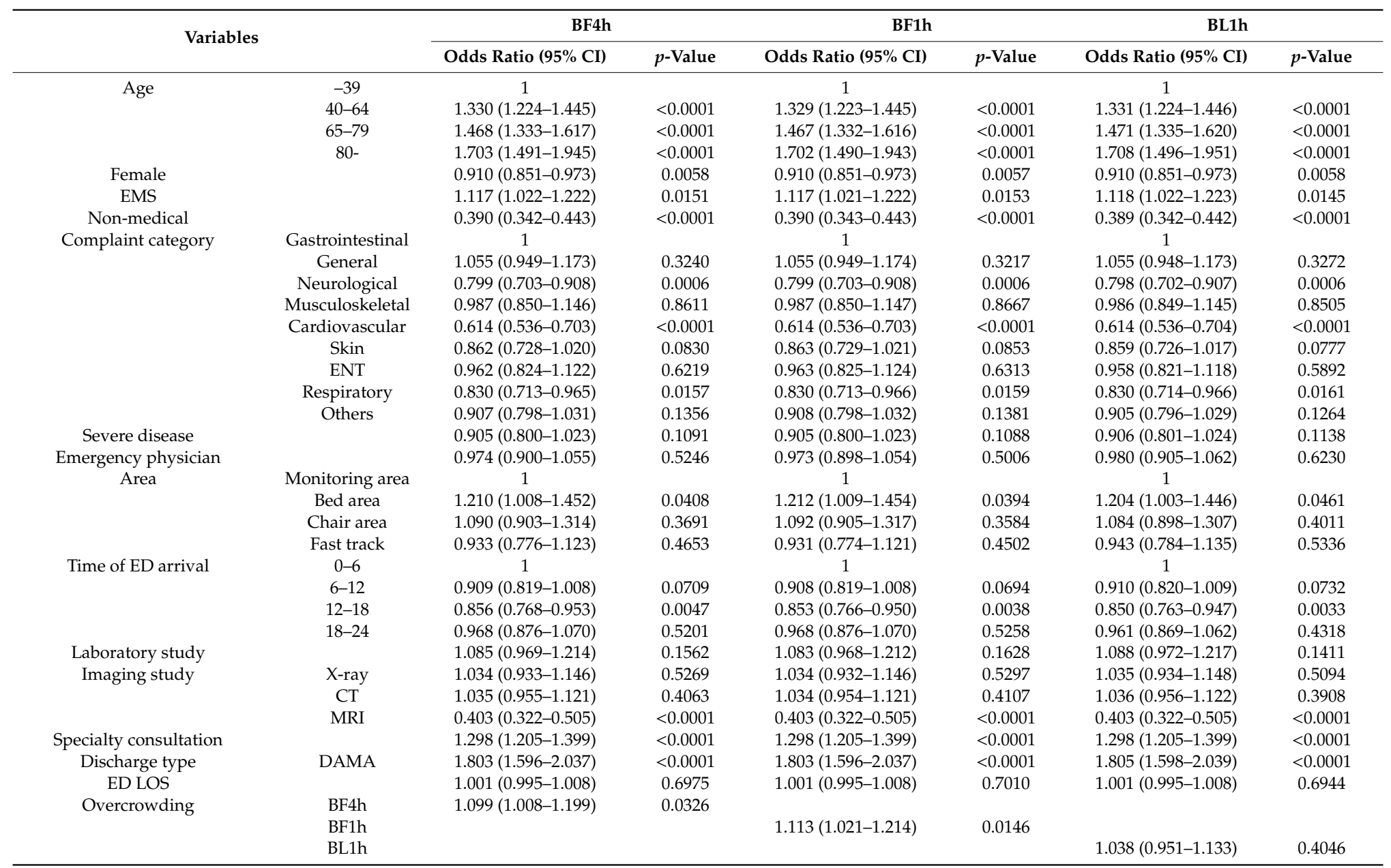

BF4h, boarding patients during first $4 \mathrm{~h}$; BF1h, boarding patients during first $1 \mathrm{~h}$; BL1h, boarding patients during last $1 \mathrm{~h}$; CI, confidence interval; EMS, emergency medical services; ENT, ears, nose and throat; ED, emergency department; CT, computed tomography; MRI, magnetic resonance imaging; DAMA, discharge against medical advice; LOS, length of stay. 


\section{Appendix E}

Table A5. Univariable logistic regression of emergency department overcrowding for return visit with admission.

\begin{tabular}{|c|c|c|c|}
\hline \multicolumn{2}{|c|}{ Variables } & \multirow{2}{*}{$\frac{\text { Odds Ratio }(95 \% \text { CI) }}{1}$} & \multirow[t]{2}{*}{$p$-Value } \\
\hline Age & -39 & & \\
\hline & $40-64$ & $1.459(1.215-1.753)$ & $<0.0001$ \\
\hline & $65-79$ & $2.091(1.716-2.546)$ & $<0.0001$ \\
\hline & $80-$ & $2.021(1.555-2.625)$ & $<0.0001$ \\
\hline Female & & $0.742(0.645-0.854)$ & $<0.0001$ \\
\hline Transfer in & & $1.404(1.106-1.784)$ & 0.0054 \\
\hline EMS & & $1.352(1.149-1.590)$ & 0.0003 \\
\hline \multirow[t]{5}{*}{ KTAS } & 1 & 1 & \\
\hline & 2 & $1.160(0.208-6.485)$ & 0.8655 \\
\hline & 3 & $1.370(0.249-7.524)$ & 0.7172 \\
\hline & 4 & $0.808(0.148-4.420)$ & 0.8054 \\
\hline & 5 & $0.280(0.050-1.564)$ & 0.1470 \\
\hline \multirow{10}{*}{$\begin{array}{c}\text { Non-medical } \\
\text { Complaint } \\
\text { category }\end{array}$} & & $0.357(0.263-0.484)$ & $<0.0001$ \\
\hline & Gastrointestinal & 1 & \\
\hline & General & $0.529(0.397-0.704)$ & $<0.0001$ \\
\hline & Neurological & $0.325(0.230-0.459)$ & $<0.0001$ \\
\hline & Cardiovascular & $0.824(0.669-1.016)$ & 0.0702 \\
\hline & Musculoskeletal & $0.404(0.295-0.554)$ & $<0.0001$ \\
\hline & ENT & $0.580(0.454-0.741)$ & $<0.0001$ \\
\hline & Respiratory & $0.115(0.067-0.198)$ & $<0.0001$ \\
\hline & Skin & $0.453(0.347-0.59)$ & $<0.0001$ \\
\hline & Others & $1.165(0.871-1.558)$ & 0.3026 \\
\hline Severe disease & & $2.640(2.104-3.311)$ & $<0.0001$ \\
\hline \multirow[t]{5}{*}{$\begin{array}{l}\text { Emergency } \\
\text { physician }\end{array}$} & & $1.428(1.237-1.649)$ & $<0.0001$ \\
\hline & Monitoring area & 1 & \\
\hline & Bed area & $0.911(0.643-1.290)$ & 0.5995 \\
\hline & Chair area & $0.586(0.417-0.825)$ & 0.0022 \\
\hline & Fast track & $0.326(0.234-0.456)$ & $<0.0001$ \\
\hline \multirow[t]{4}{*}{$\begin{array}{c}\text { Time of ED } \\
\text { arrival }\end{array}$} & $0-6$ & 1 & \\
\hline & $6-12$ & 1.335 (1.084-1.644) & 0.0066 \\
\hline & $12-18$ & 1.291 (1.044-1.597) & 0.0183 \\
\hline & $18-24$ & $1.187(0.960-1.469)$ & 0.1138 \\
\hline Weekend & & $1.060(0.915-1.227)$ & 0.4376 \\
\hline \multirow[t]{4}{*}{ Season } & Spring & 1 & \\
\hline & Summer & $1.024(0.836-1.253)$ & 0.8211 \\
\hline & Autumn & $0.988(0.811-1.203)$ & 0.9047 \\
\hline & Winter & $1.024(0.851-1.233)$ & 0.7979 \\
\hline Laboratory study & & $3.634(2.936-4.499)$ & $<0.0001$ \\
\hline \multirow[t]{3}{*}{ Imaging study } & X-ray & $2.840(2.352-3.429)$ & $<0.0001$ \\
\hline & $\mathrm{CT}$ & $1.794(1.548-2.079)$ & $<0.0001$ \\
\hline & MRI & $1.581(1.037-2.409)$ & 0.0331 \\
\hline $\begin{array}{l}\text { Specialty } \\
\text { consultation }\end{array}$ & & $2.692(2.317-3.127)$ & $<0.0001$ \\
\hline Discharge type & DAMA & $1.695(1.343-2.139)$ & $<0.0001$ \\
\hline ED arrival to area & & $1.126(0.924-1.373)$ & 0.2400 \\
\hline ED LOS & & $1.127(1.106-1.149)$ & $<0.0001$ \\
\hline \multirow[t]{9}{*}{ Overcrowding } & TF4h & $1.164(0.992-1.364)$ & 0.0619 \\
\hline & TF1h & $1.171(0.997-1.374)$ & 0.0540 \\
\hline & TL1h & $1.019(0.865-1.200)$ & 0.8223 \\
\hline & EF4h & & \\
\hline & EF1h & & \\
\hline & EL1h & & \\
\hline & $\mathrm{BF} 4 \mathrm{~h}$ & $0.999(0.839-1.190)$ & 0.9931 \\
\hline & BF1h & $1.023(0.861-1.216)$ & 0.7939 \\
\hline & BL1h & $1.077(0.904-1.284)$ & 0.4048 \\
\hline
\end{tabular}

CI, confidence interval; EMS, emergency medical services; KTAS, Korean Triage and Acuity Scale; ENT, ears, nose and throat; ED, emergency department; CT, computed tomography; MRI, magnetic resonance imaging; DAMA, discharge against medical advice; LOS, length of stay; TF4h, total patients during first $4 \mathrm{~h}$; TF1h, total patients during first $1 \mathrm{~h}$; TL1h, total patients during last $1 \mathrm{~h}$; EF4h, evaluating patients during first $4 \mathrm{~h}$; EF1h, evaluating patients during first $1 \mathrm{~h}$; EL1h, evaluating patients during last $1 \mathrm{~h}$; BF4h, boarding patients during first $4 \mathrm{~h}$; BF1h, boarding patients during first $1 \mathrm{~h}$; BL1h, boarding patients during last $1 \mathrm{~h}$. 


\section{Appendix F}

Table A6. Multivariable logistic regression of emergency department overcrowding of the number of total patients for return visit with admission.

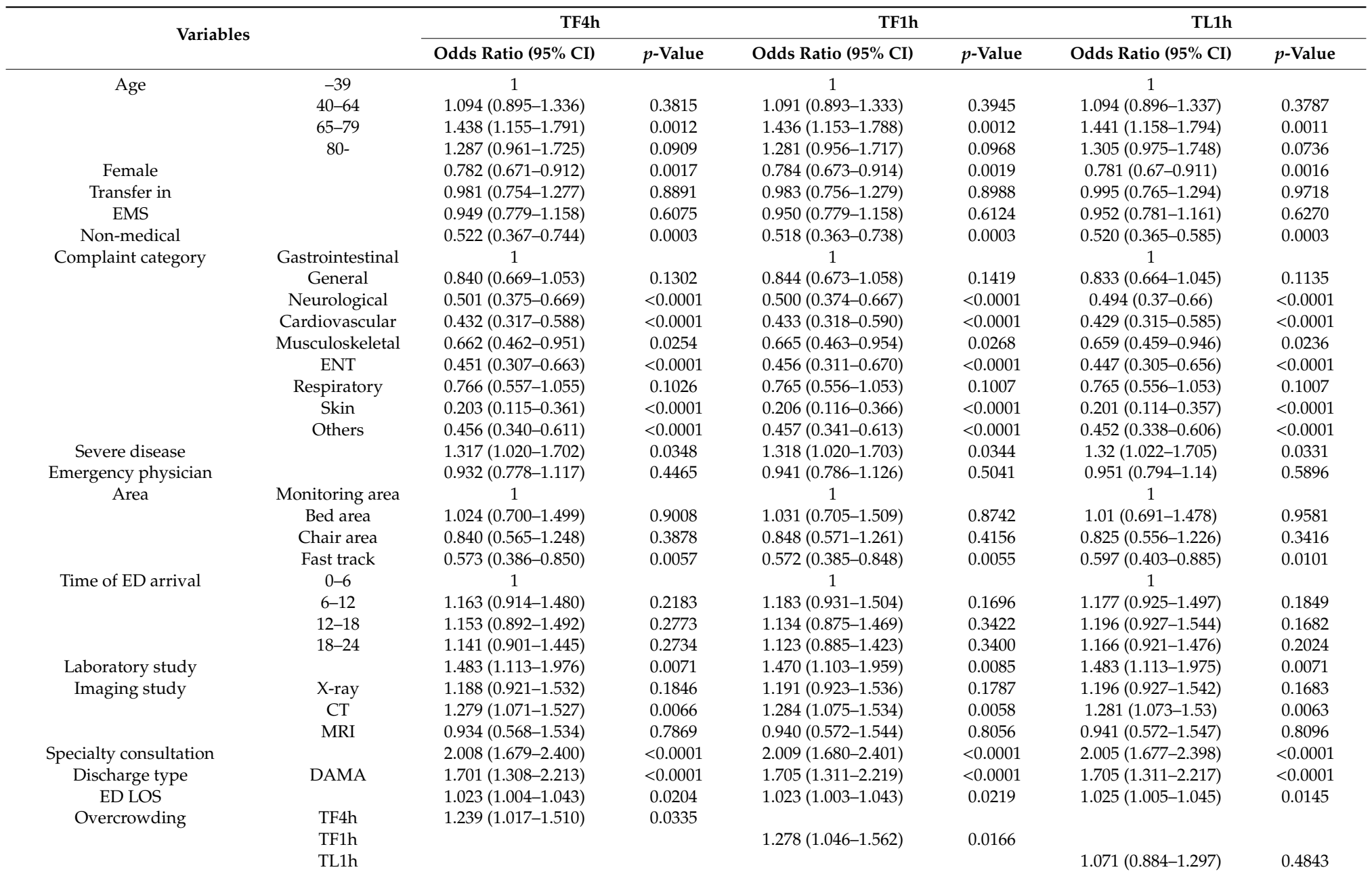

TF4h, total patients during first $4 \mathrm{~h}$; TF1h, total patients during first $1 \mathrm{~h}$; TL1h, total patients during last $1 \mathrm{~h}$; CI, confidence interval; EMS, emergency medical services; ENT, ears, nose and throat; ED, emergency department; CT, computed tomography; MRI, magnetic resonance imaging; DAMA, discharge against medical advice; LOS, length of stay. 


\section{Appendix G}

Table A7. Multivariable logistic regression of emergency department overcrowding of the number of evaluating patients for return visit with admission.

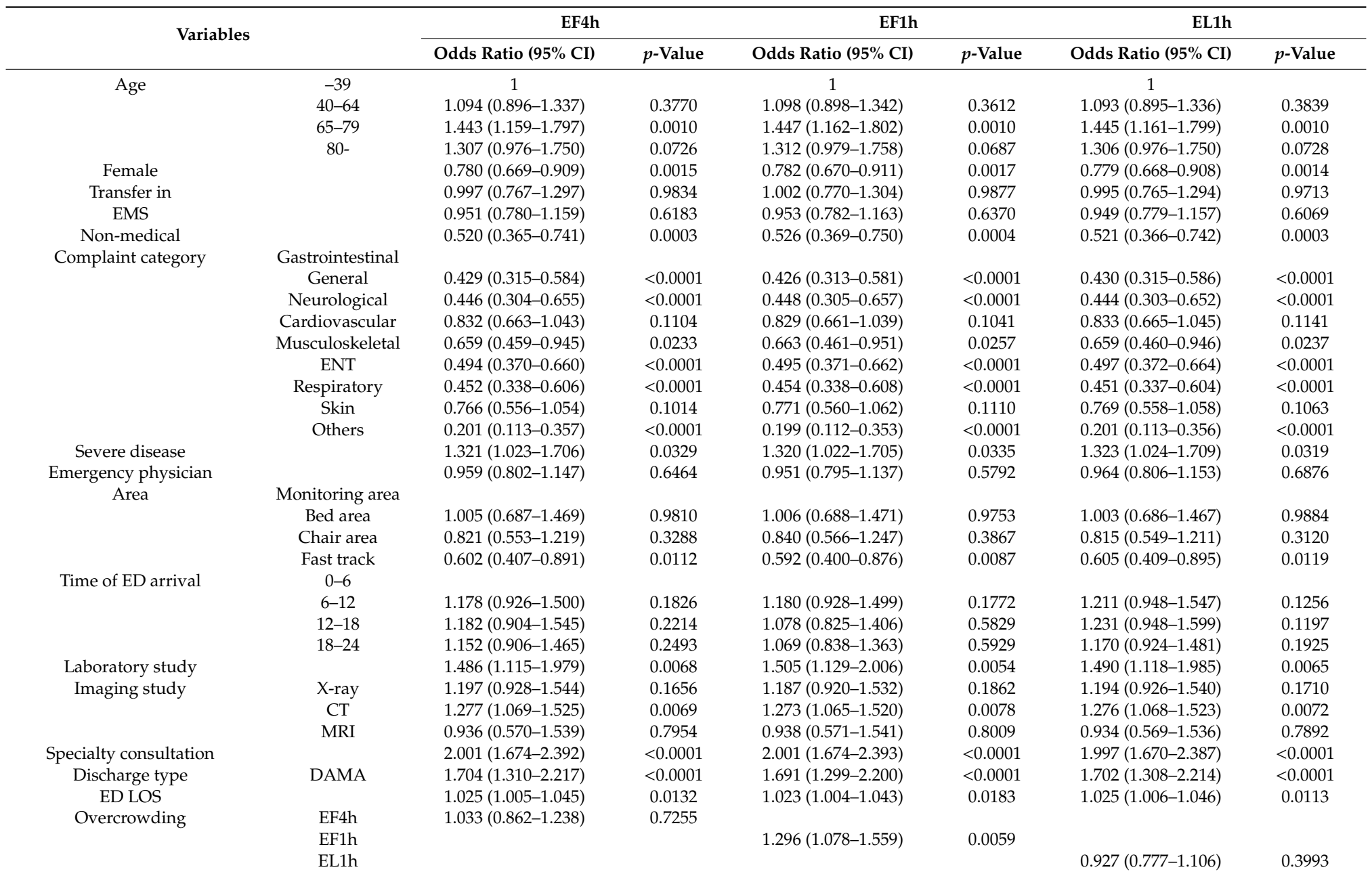

EF4h, evaluating patients during first $4 \mathrm{~h}$; EF1h, evaluating patients during first $1 \mathrm{~h}$; EL1h, evaluating patients during last $1 \mathrm{~h}$; CI, confidence interval; EMS, emergency medical services; ENT, ears, nose and throat; ED, emergency department; CT, computed tomography; MRI, magnetic resonance imaging; DAMA, discharge against medical advice; LOS, length of stay. 


\section{Appendix $\mathrm{H}$}

Table A8. Multivariable logistic regression of emergency department overcrowding of the number of boarding patients for return visit with admission.

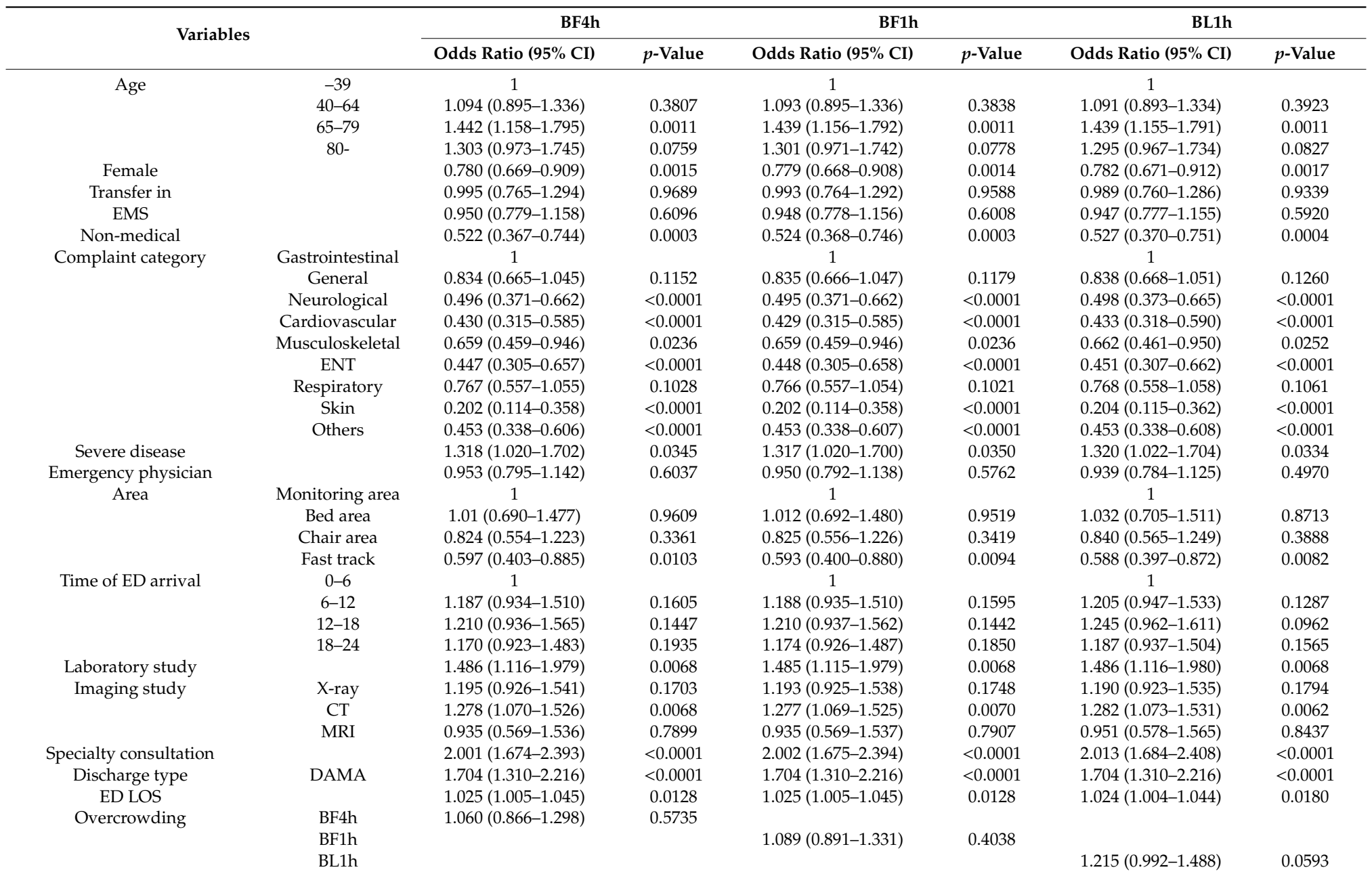

BF4h, boarding patients during first $4 \mathrm{~h}$; BF1h, boarding patients during first $1 \mathrm{~h}$; BL1h, boarding patients during last $1 \mathrm{~h}$; CI, confidence interval; EMS, emergency medical services; ENT, ears, nose and throat; ED, emergency department; CT, computed tomography; MRI, magnetic resonance imaging; DAMA, discharge against medical advice; LOS, length of stay. 


\section{References}

1. Abualenain, J.; Frohna, W.J.; Smith, M.; Pipkin, M.; Webb, C.; Milzman, D.; Pines, J.M. The prevalence of quality issues and adverse outcomes among 72-hour return admissions in the emergency department. J. Emerg. Med. 2013, 45, 281-288. [CrossRef]

2. Cheng, J.; Shroff, A.; Khan, N.; Jain, S. Emergency department return visits resulting in admission: Do they reflect quality of care? Am. J. Med. Qual. 2016, 31, 541-551. [CrossRef]

3. Pham, J.C.; Kirsch, T.D.; Hill, P.M.; DeRuggerio, K.; Hoffmann, B. Seventy-two-hour returns may not be a good indicator of safety in the emergency department: A national study. Acad. Emerg. Med. 2011, 18, 390-397. [CrossRef]

4. Trivedy, C.R.; Cooke, M.W. Unscheduled return visits (urv) in adults to the emergency department (ed): A rapid evidence assessment policy review. Emerg. Med. J. 2015, 32, 324-329. [CrossRef]

5. Nunez, S.; Hexdall, A.; Aguirre-Jaime, A. Unscheduled returns to the emergency department: An outcome of medical errors? Qual. Saf. Health Care 2006, 15, 102-108. [CrossRef]

6. Duseja, R.; Bardach, N.S.; Lin, G.A.; Yazdany, J.; Dean, M.L.; Clay, T.H.; Boscardin, W.J.; Dudley, R.A. Revisit rates and associated costs after an emergency department encounter: A multistate analysis. Ann. Intern. Med. 2015, 162, 750-756. [CrossRef]

7. Sabbatini, A.K.; Kocher, K.E.; Basu, A.; Hsia, R.Y. In-hospital outcomes and costs among patients hospitalized during a return visit to the emergency department. JAMA 2016, 315, 663-671. [CrossRef]

8. Hu, K.W.; Lu, Y.H.; Lin, H.J.; Guo, H.R.; Foo, N.P. Unscheduled return visits with and without admission post emergency department discharge. J. Emerg. Med. 2012, 43, 1110-1118. [CrossRef] [PubMed]

9. Jimenez-Puente, A.; Del Rio-Mata, J.; Arjona-Huertas, J.L.; Mora-Ordonez, B.; Martinez-Reina, A.; Martinez Del Campo, M.; Nieto-de Haro, L.; Lara-Blanquer, A. Which unscheduled return visits indicate a quality-of-care issue? Emerg. Med. J. 2017, 34, 145-150. [CrossRef] [PubMed]

10. Augustine, E.M.; Bekker, T.D.; Goel, A.; Breslin, K.A.; Chamberlain, J.M. A survey of return visits to the pediatric emergency department: The caretakers' perspective. Pediatr. Emerg. Care 2018, 34, 27-32. [CrossRef] [PubMed]

11. Blom, M.C.; Jonsson, F.; Landin-Olsson, M.; Ivarsson, K. Associations between in-hospital bed occupancy and unplanned 72-h revisits to the emergency department: A register study. Int. J. Emerg. Med. 2014, 7, 25. [CrossRef] [PubMed]

12. Pierce, J.M.; Kellerman, A.L.; Oster, C. "Bounces": An analysis of short-term return visits to a public hospital emergency department. Ann. Emerg. Med. 1990, 19, 752-757. [CrossRef]

13. Cardin, S.; Afilalo, M.; Lang, E.; Collet, J.P.; Colacone, A.; Tselios, C.; Dankoff, J.; Guttman, A. Intervention to decrease emergency department crowding: Does it have an effect on return visits and hospital readmissions? Ann. Emerg. Med. 2003, 41, 173-185. [CrossRef] [PubMed]

14. Gordon, J.A.; Billings, J.; Asplin, B.R.; Rhodes, K.V. Safety net research in emergency medicine: Proceedings of the academic emergency medicine consensus conference on "the unraveling safety net". Acad. Emerg. Med. 2001, 8, 1024-1029. [CrossRef] [PubMed]

15. Trzeciak, S.; Rivers, E.P. Emergency department overcrowding in the united states: An emerging threat to patient safety and public health. Emerg. Med. J. 2003, 20, 402-405. [CrossRef]

16. Epstein, S.K.; Huckins, D.S.; Liu, S.W.; Pallin, D.J.; Sullivan, A.F.; Lipton, R.I.; Camargo, C.A., Jr. Emergency department crowding and risk of preventable medical errors. Intern. Emerg. Med. 2012, 7, 173-180. [CrossRef]

17. Kulstad, E.B.; Sikka, R.; Sweis, R.T.; Kelley, K.M.; Rzechula, K.H. Ed overcrowding is associated with an increased frequency of medication errors. Am. J. Emerg. Med. 2010, 28, 304-309. [CrossRef]

18. Di Somma, S.; Paladino, L.; Vaughan, L.; Lalle, I.; Magrini, L.; Magnanti, M. Overcrowding in emergency department: An international issue. Intern. Emerg. Med. 2015, 10, 171-175. [CrossRef]

19. Verelst, S.; Pierloot, S.; Desruelles, D.; Gillet, J.B.; Bergs, J. Short-term unscheduled return visits of adult patients to the emergency department. J. Emerg. Med. 2014, 47, 131-139. [CrossRef]

20. Hayward, J.; Hagtvedt, R.; Ma, W.; Gauri, A.; Vester, M.; Holroyd, B.R. Predictors of admission in adult unscheduled return visits to the emergency department. West. J. Emerg. Med. 2018, 19, 912-918. [CrossRef] [PubMed] 
21. Hutchinson, C.L.; McCloughen, A.; Curtis, K. Incidence, characteristics and outcomes of patients that return to emergency departments. An integrative review. Australas. Emerg. Care 2019, 22, 47-68. [CrossRef] [PubMed]

22. Verelst, S.; Wouters, P.; Gillet, J.B.; Van den Berghe, G. Emergency department crowding in relation to in-hospital adverse medical events: A large prospective observational cohort study. J. Emerg. Med. 2015, 49, 949-961. [CrossRef] [PubMed]

23. Wu, C.L.; Wang, F.T.; Chiang, Y.C.; Chiu, Y.F.; Lin, T.G.; Fu, L.F.; Tsai, T.L. Unplanned emergency department revisits within $72 \mathrm{~h}$ to a secondary teaching referral hospital in taiwan. J. Emerg. Med. 2010, 38, 512-517. [CrossRef] [PubMed]

24. Van der Linden, M.C.; Lindeboom, R.; de Haan, R.; van der Linden, N.; de Deckere, E.R.; Lucas, C.; Rhemrev, S.J.; Goslings, J.C. Unscheduled return visits to a dutch inner-city emergency department. Int. J. Emerg. Med. 2014, 7, 23. [CrossRef]

25. Huggins, C.; Robinson, R.D.; Knowles, H.; Cizenski, J.; Mbugua, R.; Laureano-Phillips, J.; Schrader, C.D.; Zenarosa, N.R.; Wang, H. Large observational study on risks predicting emergency department return visits and associated disposition deviations. Clin. Exp. Emerg. Med. 2019, 6, 144-151. [CrossRef]

26. White, D.; Kaplan, L.; Eddy, L. Characteristics of patients who return to the emergency department within $72 \mathrm{~h}$ in one community hospital. Adv. Emerg. Nurs. J. 2011, 33, 344-353. [CrossRef]

27. Kuan, W.S.; Mahadevan, M. Emergency unscheduled returns: Can we do better? Singapore Med. J. 2009, 50, 1068-1071.

28. Moskop, J.C.; Sklar, D.P.; Geiderman, J.M.; Schears, R.M.; Bookman, K.J. Emergency department crowding, part 1-concept, causes, and moral consequences. Ann. Emerg. Med. 2009, 53, 605-611. [CrossRef]

29. Chan, S.S.; Cheung, N.K.; Graham, C.A.; Rainer, T.H. Strategies and solutions to alleviate access block and overcrowding in emergency departments. Hong Kong Med. J. 2015, 21, 345-352. [CrossRef]

30. Calder, L.A.; Forster, A.J.; Stiell, I.G.; Carr, L.K.; Perry, J.J.; Vaillancourt, C.; Brehaut, J. Mapping out the emergency department disposition decision for high-acuity patients. Ann. Emerg. Med. 2012, 60, 567-576. [CrossRef]

31. Blom, M.C.; Jonsson, F.; Landin-Olsson, M.; Ivarsson, K. The probability of patients being admitted from the emergency department is negatively correlated to in-hospital bed occupancy-A registry study. Int. J. Emerg. Med. 2014, 7, 8. [CrossRef] [PubMed]

32. Blom, M.C.; Landin-Olsson, M.; Lindsten, M.; Jonsson, F.; Ivarsson, K. Patients presenting at the emergency department with acute abdominal pain are less likely to be admitted to inpatient wards at times of access block: A registry study. Scand. J. Trauma Resusc. Emerg. Med. 2015, 23, 78. [CrossRef] [PubMed]

33. Abir, M.; Goldstick, J.E.; Malsberger, R.; Williams, A.; Bauhoff, S.; Parekh, V.I.; Kronick, S.; Desmond, J.S. Evaluating the impact of emergency department crowding on disposition patterns and outcomes of discharged patients. Int. J. Emerg. Med. 2019, 12, 4. [CrossRef] [PubMed]

34. Staib, A.; Sullivan, C.; Griffin, B.; Bell, A.; Scott, I. Report on the 4-h rule and national emergency access target (neat) in australia: Time to review. Aust. Health Rev. 2016, 40, 319-323. [CrossRef] [PubMed]

35. Alishahi Tabriz, A.; Birken, S.A.; Shea, C.M.; Fried, B.J.; Viccellio, P. What is full capacity protocol, and how is it implemented successfully? Implement. Sci. 2019, 14, 73. [CrossRef]

36. Willard, E.; Carlton, E.F.; Moffat, L.; Barth, B.E. A full-capacity protocol allows for increased emergency patient volume and hospital admissions. J. Emerg. Nurs. 2017, 43, 413-418. [CrossRef]

37. McCusker, J.; Vadeboncoeur, A.; Levesque, J.F.; Ciampi, A.; Belzile, E. Increases in emergency department occupancy are associated with adverse 30-day outcomes. Acad. Emerg. Med. 2014, 21, 1092-1100. [CrossRef]

38. Rhodes, K.V.; Vieth, T.; He, T.; Miller, A.; Howes, D.S.; Bailey, O.; Walter, J.; Frankel, R.; Levinson, W. Resuscitating the physician-patient relationship: Emergency department communication in an academic medical center. Ann. Emerg. Med. 2004, 44, 262-267. [CrossRef]

39. Newnham, H.; Barker, A.; Ritchie, E.; Hitchcock, K.; Gibbs, H.; Holton, S. Discharge communication practices and healthcare provider and patient preferences, satisfaction and comprehension: A systematic review. Int. J. Qual. Health Care 2017, 29, 752-768. [CrossRef]

40. Petre, B.; Margat, A.; Servotte, J.C.; Guillaume, M.; Gagnayre, R.; Ghuysen, A. Patient education in the emergency department: Take advantage of the teachable moment. Adv. Health Sci. Educ. Theory Pract. 2019. [CrossRef] 
41. Atzema, C.L.; Austin, P.C.; Wu, L.; Brzozowski, M.; Feldman, M.J.; McDonnell, M.; Mazurik, L. Speak fast, use jargon, and don't repeat yourself: A randomized trial assessing the effectiveness of online videos to supplement emergency department discharge instructions. PLoS ONE 2013, 8, e77057. [CrossRef] [PubMed]

42. Navanandan, N.; Schmidt, S.K.; Cabrera, N.; DiStefano, M.C.; Mistry, R.D. The caregiver perspective on unscheduled 72-hour return visits to pediatric acute care sites: A focus on discharge processes. Acad. Pediatr. 2017, 17, 755-761. [CrossRef] [PubMed]

43. Engel, K.G.; Heisler, M.; Smith, D.M.; Robinson, C.H.; Forman, J.H.; Ubel, P.A. Patient comprehension of emergency department care and instructions: Are patients aware of when they do not understand? Ann. Emerg. Med. 2009, 53, 454-461. [CrossRef]

44. Yoo, D.-K.; Suh, S.-W. The effect of medical service quality and perceived risk on customer satisfaction, repurchase intention, and churn intention as to hospital sizes. J. Korea Serv. Manag. Soc. 2009, 10, 97-130.

45. Seol, D.-W.; Yu, S.-H.; Park, E.-C.; Kim, E.-S. Factors related to willingness of choosing the same hospital. Korean J. Hosp. Manag. 1997, 2, 65-79.

46. Lindsay, P.; Schull, M.; Bronskill, S.; Anderson, G. The development of indicators to measure the quality of clinical care in emergency departments following a modified-delphi approach. Acad. Emerg. Med. 2002, 9, 1131-1139. [CrossRef] [PubMed]

47. McCarthy, M.L.; Ding, R.; Pines, J.M.; Zeger, S.L. Comparison of methods for measuring crowding and its effects on length of stay in the emergency department. Acad. Emerg. Med. 2011, 18, 1269-1277. [CrossRef]

48. Lauks, J.; Mramor, B.; Baumgartl, K.; Maier, H.; Nickel, C.H.; Bingisser, R. Medical team evaluation: Effect on emergency department waiting time and length of stay. PLOS ONE 2016, 11, e0154372. [CrossRef]

(C) 2020 by the authors. Licensee MDPI, Basel, Switzerland. This article is an open access article distributed under the terms and conditions of the Creative Commons Attribution (CC BY) license (http://creativecommons.org/licenses/by/4.0/). 